\title{
CHARACTERIZATION OF THE RADIATION SHIELDING PROPERTIES OF US AND RUSSIAN EVA SUITS
}

E. R. Benton, E.V. Benton and A.L. Frank

$$
\text { prepared for }
$$

Lawrence Berkeley National Laboratory

Contract No. DE-AC03-76SF00098

Subcontract No. 6501333

\section{ERIL RESEARCH, INC.}

P.๑. $B \square \times 150788$

SAN RAFAEL, CA $94915-0788$

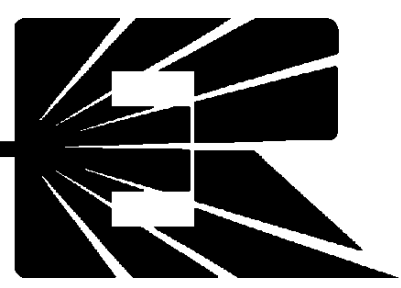




\title{
CHARACTERIZATION OF THE RADIATION SHIELDING PROPERTIES OF US AND RUSSIAN EVA SUITS
}

\author{
E. R. Benton, E.V. Benton, and A.L. Frank \\ Eril Research, Inc., San Rafael, CA-94915-0788
}

\begin{abstract}
Reported herein are results from the Eril Research, Inc. (ERI) participation in the NASA Johnson Space Center sponsored study characterizing the radiation shielding properties of the two types of space suit that astronauts are wearing during the EVA on-orbit assembly of the International Space Station (ISS). Measurements using passive detectors were carried out to assess the shielding properties of the US EMU Suit and the Russian Orlan-M suit during irradiations of the suits and a tissue equivalent phantom to monoenergetic proton and electron beams at the Loma Linda University Medical Center (LLUMC). During irradiations of $6 \mathrm{MeV}$ electrons and $60 \mathrm{MeV}$ protons, absorbed dose as a function of depth was measured using TLDs exposed behind swatches of the two suit materials and inside the two EVA helmets. Considerable reduction in electron dose was measured behind all suit materials in exposures to $6 \mathrm{MeV}$ electrons. Slowing of the proton beam in the suit materials led to an increase in dose measured in exposures to $60 \mathrm{MeV}$ protons. During $232 \mathrm{MeV}$ proton irradiations, measurements were made with TLDs and CR-39 PNTDs at five organ locations inside a tissue equivalent phantom, exposed both with and without the two EVA suits. The EVA helmets produce a 13 to $27 \%$ reduction in total dose and a 0 to $25 \%$ reduction in dose equivalent when compared to measurements made in the phantom head alone. Differences in dose and dose equivalent between the suit and non-suit irradiations for the lower portions of the two EVA suits tended to be smaller. Protoninduced target fragmentation was found to be a significant source of increased dose equivalent, especially within the two EVA helmets, and average quality factor inside the EMU and Orlan-M helmets was 2 to $14 \%$ greater than that measured in the bare phantom head.
\end{abstract}

\section{INTRODUCTION}

The on-orbit assembly of the International Space Station (ISS) requires a level of extravehicular activity (EVA) unprecedented in the history of human space flight. The assembly of the ISS is anticipated to require over one thousand hours of EVA spanning a five year period - more than two and a half times more than the total EVA time accrued by all astronauts and cosmonauts to date [1]. This large amount of EVA will expose space workers to the radiation environment in low-Earth orbit present on the outside of the ISS. During EVA astronauts and cosmonauts are shielding only by the material of their suits and lack the benefit of the greater shielding provided by the mass of the 
station. In order to assess the radiation shielding effectiveness of the US and Russian EVA suits, both of which will be used during ISS assembly, one suit of each type was brought to the Loma Linda University Medical Center (LLUMC) and exposed to beams of monoenergetic protons at two energies and to a beam of monoenergetic electrons at one energy. At the behest of the NASA Johnson Space Center's Space Radiation Health Project, Eril Research, Inc. (ERI) participated with a number of other investigators in characterizing the radiation shielding properties of the two EVA suits.

In the $51.56^{\circ}$ inclination, $\sim 400 \mathrm{~km}$ altitude orbit of the ISS, it is trapped protons and electrons which are of principle concern to astronaut health and safety during EVA. Trapped electrons range in energy up to $\sim 6 \mathrm{MeV}$ and are encountered while the station is at high latitudes and passing through the cusps of the trapped electron belt [2]. The spectrum of trapped protons extends from several $\mathrm{MeV}$ up to several hundred $\mathrm{MeV}$, with a broad peak between $\sim 150$ and $\sim 250 \mathrm{MeV}$. The trapped proton flux is greatest when the ISS is passing through the South Atlantic Anomaly (SAA), a region off the coast of Brazil where the Earth's magnetic field dips unusually low, allowing trapped protons to intersect the orbit of the ISS [2]. All but the most energetic electrons and a substantial fraction of the trapped proton flux are attenuated within the shielding represented by the outer structure of the ISS. However, during EVA astronauts are protected only by the shielding provided by their suits, which is substantially less than that provided by the structure of the ISS. This decreased shielding permits lower energy particles to penetrate the body of the astronaut, increasing his total radiation exposure. Doses measured in the Russian Orlan suit during a 1997 EVA on the Russian Mir Orbital Station using the Hungarian Pille portable TLD system were three to four and half times greater than that measured inside the Mir during the same time period [3].

Two types of EVA suit were tested. The Extravehicular Mobility Suit (EMU), manufactured for NASA by ILC Dover, is the current design of US EVA suit used aboard the Space Shuttle and the ISS. The Orlan (Eagle) -M suit, produced by NPP Zvezda, is the current Russian EVA suit and has been previously used aboard the Mir Orbital Station. An example of each suit was used in radiation exposures at LLUMC. In addition, swatches of suit material from each type of suit were used in some of the exposures. A tissue equivalent human phantom was used to simulate an astronaut body. Detectors were exposed at specific organ sites of interest in the phantom while wearing the suits.

Radiation detectors were exposed behind portions of the suit to monoenergetic electrons of $6 \mathrm{MeV}$ and to monoenergetic protons of two energies: $60 \mathrm{MeV}$ and $232 \mathrm{MeV}$. The choice of electron and proton energies was dictated both by the radiation environment present outside the station in the ISS orbit and by the capabilities of the radiation facilities at LLUMC.

The objective of the ERI measurements made during both the $6 \mathrm{MeV}$ electron and 60 $\mathrm{MeV}$ proton irradiations was to measure dose as a function of depth behind each of the two EVA suits and inside the two EVA helmets. For these measurements, stacks of thermoluminescent detectors (TLDs) were exposed perpendicular to the electron and proton beams behind swatches of EVA suit material and behind the visors of the EVA 
helmets. Dose as a function of TLD position in each stack was measured and TLD position was then converted to depth in water.

The objectives of the ERI measurements made during the $232 \mathrm{MeV}$ proton irradiations were: 1) to measure total dose, dose equivalent and average quality factor at several specific organ sites inside the tissue equivalent phantom both with and without the EVA suits; 2) to assess the contribution to total dose and dose equivalent from proton-induced, high-LET target fragmentation; and 3) to assess the contribution to total dose and dose equivalent from thermal $(\leq 0.2 \mathrm{eV})$ and epithermal $\left(0.2 \mathrm{eV}<\mathrm{E}_{\mathrm{n}}<1 \mathrm{MeV}\right)$ neutrons. To meet these objectives, two types of passive radiation detector were used. CR-39 plastic nuclear track detector (PNTD) was used to measure the LET spectrum, dose and dose equivalent from charged particles of $\mathrm{LET}_{\infty} \mathrm{H}_{2} \mathrm{O} \geq 5 \mathrm{keV} / \mu \mathrm{m}$. TLDs were used to measure absorbed dose and to assess the contribution to dose from thermal and epithermal neutrons. Measurements from the two detector types were combined to yield total dose, dose equivalent and average quality factor, and to assess the contribution to total dose and dose equivalent from high-LET target fragments.

\section{EXPERIMENT}

\subsection{Detectors}

\subsubsection{Thermoluminescent Detectors}

TLDs were used to measure absorbed dose in all three types of irradiation. For the $6 \mathrm{MeV}$ electron and $60 \mathrm{MeV}$ proton irradiations, TLD-700 ( $\left.{ }^{7} \mathrm{LiF}\right)$ was used. For the $232 \mathrm{MeV}$ proton irradiation, two types of TLD materials, TLD-700 $\left({ }^{7} \mathrm{LiF}\right)$ and TLD-600 $\left({ }^{6} \mathrm{LiF}\right)$, were used. The difference in the responses of TLD-700 and TLD-600 is due to the high cross section of ${ }^{6} \mathrm{Li}$ in the TLD-600 for absorption of thermal and epithermal neutrons in the ${ }^{6} \mathrm{Li}(\mathrm{n}, \alpha)^{3} \mathrm{H}$ reaction. Both TLD types measure total gamma ray/charged particle absorbed dose while the TLD-600 measures an additional dose proportional to low energy neutron fluences present during the exposure. The sensitivity to neutrons is poor in TLD-700. The use of TLD-600 covered and uncovered by Gd foil allows thermal neutron induced response to be separated from epithermal response. Following the irradiations, the TLDs were read out using a standard Harshaw-4000 TLD reader. Each TLD was individually calibrated using ERI's ${ }^{137} \mathrm{Cs} \gamma$-ray source.

\subsubsection{CR-39 Plastic Nuclear Track Detectors}

CR-39 PNTDs were used to measure the LET spectra, dose, and dose equivalent from charged particles of $\mathrm{LET}_{\infty} \mathrm{H}_{2} \mathrm{O} \geq 5 \mathrm{keV} / \mu \mathrm{m}$ during the $232 \mathrm{MeV}$ proton irradiations. The protons produced by the LLUMC synchrotron range in energy from 50 to $250 \mathrm{MeV}$ corresponding to an LET between 1.3 and $0.4 \mathrm{keV} / \mu \mathrm{m}$. Particles with LET below $5 \mathrm{keV} / \mu \mathrm{m}$ do not register in CR-39. Thus the primary protons produced by the accelerator are not recorded in the detector. The vast majority of tracks formed in the detector are 
from secondary particles - target fragments-produced in interactions between the primary protons and the nuclei of the stopping medium (EVA suit, tissue equivalent phantom and the PNTD itself in this case). The LET spectrum measured in CR-39 PNTDs exposed to $232 \mathrm{MeV}$ protons is primarily the result of target fragmentation.

Four layers of CR-39 PNTD were included in each passive detector stack; two layers were used to measure the LET spectrum and two layers were held in reserve should problems arise during chemical processing of the first two layers. One CR-39 PNTD was chemically processed for a short duration (36 hours) to reveal tracks from short-range, high-LET secondary particles, while the second CR-39 PNTD was processed for a longer duration (168 hours) to reveal small tracks produced by particles with LETs down to the $5 \mathrm{keV} / \mu \mathrm{m}$ threshold. For both processing durations, chemical processing was carried out in a solution of $6.25 \mathrm{~N} \mathrm{NaOH}$ at $50^{\circ} \mathrm{C}$.

Readout and analysis of the processed CR-39 layers was carried out using a semiautomated ELBEK track detector analysis system. The ELBEK system uses a standard optical microscope equipped with transmitted illumination, computer-controlled focus and $x-y$ stage. The surface of each detector was scanned and all tracks within the scanned area of the detector surface were measured. The LET spectrum for each detector was generated using an empirically determined detector response function. Separate LET spectra were generated for both the short and long duration etch detectors. These two spectra were then combined to produce one total LET spectrum for that particular detector stack.

Because CR-39 possesses an LET-dependent angular response, the detector stacks exposed to $232 \mathrm{MeV}$ protons were irradiated at three angles. Particles of LET near the $5 \mathrm{keV} / \mu \mathrm{m}$ detection threshold only form tracks in CR-39 when the particles penetrate the detector at an angle near normal $\left(90^{\circ}\right)$ to the detector surface. This registration angle widens with increasing LET so that particles of LET significantly greater than the threshold will form tracks at angles much shallower than $90^{\circ}$. In exposures to isotropic radiation fields like that found in low Earth orbit, the angular dependence on LET is compensated for in the data analysis software. However in accelerator-based experiments, the direction of the incident beam produces additional angular constraints. One target fragmentation component-the evaporation component-produces an isotropic distribution of particles and the angle of the incident proton beam relative to the CR-39 detector is unimportant. However, a second target fragmentation component tends to produce secondaries in the forward direction of the beam. This component mostly consists of knock-out secondaries including secondary protons, neutrons and alpha particles. The result of the combined effects of the LET dependence on the angular sensitivity of CR-39 with the preferred forward direction of target fragmentation in the detector's frame of reference leads to the detector possessing a larger number of low LET target fragments when it is exposed at $90^{\circ}$ relative to the beam than when it is exposed at shallower angles.

To compensate for this added angular constraint the detector stacks irradiated inside the phantom were exposed at multiple angles. Each detector stack was exposed to $1 / 3$ of the 
total desired dose at normal $\left(90^{\circ}\right), 1 / 3$ of the dose at an angle $30^{\circ}$ counter clockwise to normal, and $1 / 3$ of the dose at an angle of $45^{\circ}$ clockwise of normal. The exposures angles are illustrated in Figure 1. An exception were the exposures made to detector stacks positioned at the eye of the phantom. Because the primary proton beam passed through the back of the phantom head before emerging at the eye and into the detector, it was not possible to accurately align the beam at the two off-axis angles and the entire exposure was made at $90^{\circ}$.

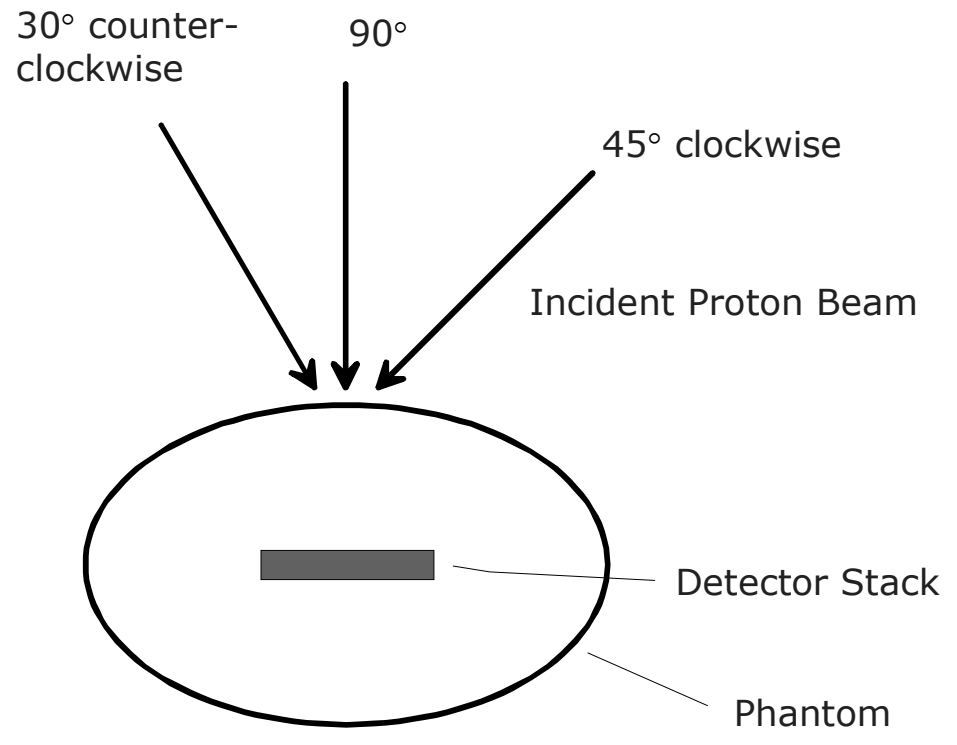

Figure 1. Due to the LET-dependent angular sensitivity of CR-39 PNTD, most of the detectors were exposed a three angles as shown above.

\subsubsection{Dose and Dose Equivalent from Combined CR-39 PNTD/TLD Measurements}

TLDs measure total absorbed dose, but have a reduced sensitivity to high LET particles (LET $\geq 5 \mathrm{keV} / \mu \mathrm{m}$ ) [4]. Also, TLDs yield no Quality Factor (QF) information needed to determine dose equivalent. PNTDs measure LET spectra (LET $>5 \mathrm{keV} / \mu \mathrm{m}$ ) from charged particles, but are insensitive to high-energy protons $(\geq 12 \mathrm{MeV})$ where much of the dose is concentrated. Measurements from these two types of detector are combined to give total dose (corrected for high-LET particles), dose equivalent, and average quality factor.

The loss of sensitivity in the TLDs can be found by dividing the measured dose into two regions; LET $<5 \mathrm{keV} / \mu \mathrm{m}$ where $\mathrm{QF}=1$ and $\mathrm{LET} \geq 5 \mathrm{keV} / \mu \mathrm{m}$ where $\mathrm{QF}>1$. In fact, $\mathrm{QF}>1$ for LET $>3.5 \mathrm{keV} / \mu \mathrm{m}$, but the above assumption results in an insignificant error for the particle spectra in these measurements. The dose from high LET particles can be derived from the LET spectra measured by the PNTDs. The measurement efficiency of the high LET dose can be found from: 
Eril Research, Inc.

$$
\bar{\varepsilon}=\frac{\sum_{5 \mathrm{keV} / \mu \mathrm{m}}^{\mathrm{LET}_{\mathrm{Max}}} \varepsilon(\mathrm{LET}) \mathrm{D}(\mathrm{LET})}{\mathrm{D}_{\mathrm{PNTD}}}
$$

where, $\varepsilon\left(\right.$ LET) is the empirically derived, LET-dependent efficiency for ${ }^{7} \mathrm{LiF}$ TLDs, $\mathrm{D}(\mathrm{LET})$ is the differential dose spectrum generated from the PNTD measurements and $\mathrm{D}_{\text {PNTD }}$ is the integrated dose measured by the PNTDs [4]. Total corrected dose is found from the low LET and high LET doses as follows:

and

$$
\mathrm{D}_{\mathrm{L}}=\mathrm{D}_{\mathrm{TLD}}-\varepsilon \mathrm{D}_{\mathrm{PNTD}}
$$

$$
\mathrm{D}_{\mathrm{T}}=\mathrm{D}_{\mathrm{L}}+\mathrm{D}_{\mathrm{PNTD}}
$$

The total dose equivalent is then:

$$
\mathrm{H}_{\mathrm{T}}=\mathrm{D}_{\mathrm{L}}+\mathrm{H}_{\mathrm{PNTD}}
$$

where, $\mathrm{H}_{\text {PNTD }}$ is the integrated dose equivalent measured by the PNTDs. Average quality factor is then be determined by:

$$
\mathrm{QF}=\mathrm{H}_{\mathrm{T}} / \mathrm{D}_{\mathrm{T}}
$$

\subsection{Irradiations to $6 \mathrm{MeV}$ Electrons and $60 \mathrm{MeV}$ Protons}

Measurements of dose as a function of depth within the two types of helmet and behind the two suit materials were made with stacks of TLD-700 $\left({ }^{7} \mathrm{LiF}\right)$. The stacks were composed of approximately 20 thin $(0.00914 \mathrm{~cm})$ TLDs and 12 thick $(0.0889 \mathrm{~cm})$ TLDs. The TLDs were contained in rectangular slots milled in acrylic cylinders. A top window of $7.5 \mu \mathrm{m}$ Kapton (Al) foil sealed the cylinders. The TLD stack assembly is illustrated in Figure 2. The stacks were exposed to a $6 \mathrm{MeV}$ electron beams from an electronic linac and to a $60 \mathrm{MeV}$ proton beam from the LLUMC proton synchrotron incident through selected parts of the suits. The exposed TLDs were read out sequentially to yield a depth dose distribution inside the suit. The $6 \mathrm{MeV}$ electron irradiations are summarized in Table 1, while the $60 \mathrm{MeV}$ proton irradiations are summarized in Table 2. Actual doses in each table are those measured by in-line active dosimetry.

Table 1. Electron exposures made to measure dose as a function of tissue depth inside the EMU and Orlan-M helmets and behind swatches of the EMU suit and Orlan-M suit material.

\begin{tabular}{l|l|c|c|c}
\hline Selected Site & Suit & Particle & Energy & Actual Dose \\
\hline \hline Suit swatch & EMU & $\mathrm{e}^{-}$ & $6 \mathrm{MeV}$ & $10 \mathrm{cGy}$ \\
\hline Eye/Helmet & EMU & $\mathrm{e}^{-}$ & $6 \mathrm{MeV}$ & $10 \mathrm{cGy}$ \\
\hline Suit swatch & Orlan-M & $\mathrm{e}^{-}$ & $6 \mathrm{MeV}$ & $10 \mathrm{cGy}$ \\
\hline Eye/Helmet & Orlan-M & $\mathrm{e}^{-}$ & $6 \mathrm{MeV}$ & $10 \mathrm{cGy}$ \\
\hline
\end{tabular}


Table 2. Low-energy proton exposures made to measure dose as a function of tissue depth inside the EMU and Orlan-M helmets and behind swatches of the EMU suit and Orlan-M suit material.

\begin{tabular}{l|l|c|c|c}
\hline Selected Site & Suit & Particle & Energy & Actual Dose \\
\hline \hline Suit swatch & EMU & $\mathrm{p}^{+}$ & $60 \mathrm{MeV}$ & $10.02 \mathrm{cGy}$ \\
\hline Eye/Helmet & EMU & $\mathrm{p}^{+}$ & $60 \mathrm{MeV}$ & $9.99 \mathrm{cGy}$ \\
\hline Suit swatch & Orlan-M & $\mathrm{p}^{+}$ & $60 \mathrm{MeV}$ & $10.03 \mathrm{cGy}$ \\
\hline Eye/Helmet & Orlan-M & $\mathrm{p}^{+}$ & $60 \mathrm{MeV}$ & $10.03 \mathrm{cGy}$ \\
\hline
\end{tabular}

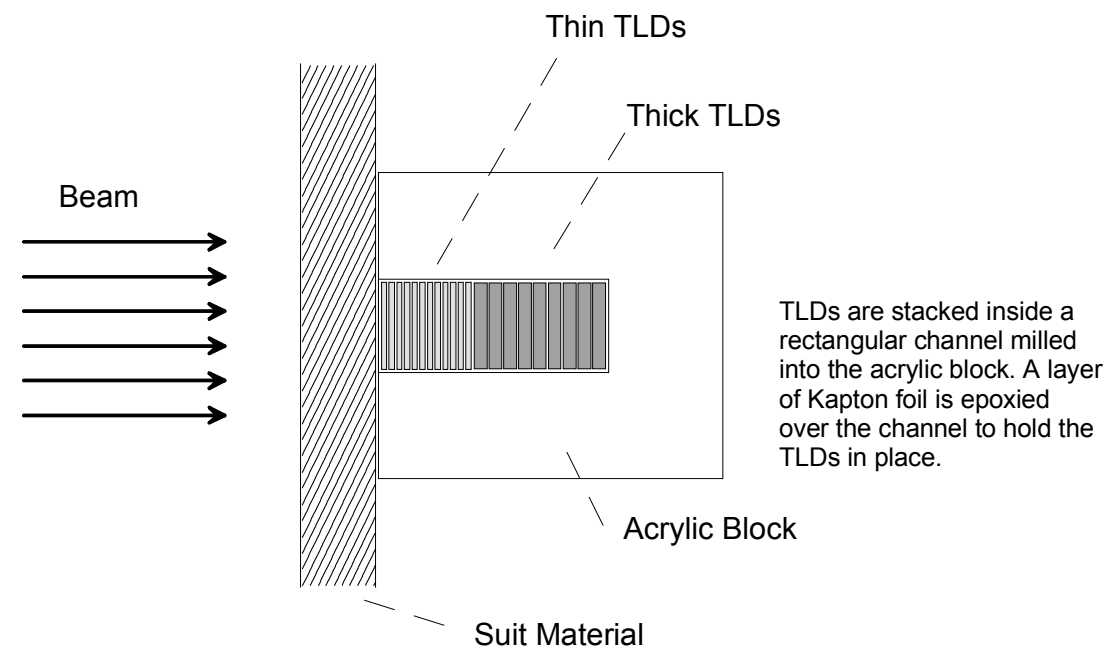

Figure 2. TLD Stack used in making dose/depth measurements behind EVA suit material and helmets exposed to $6 \mathrm{MeV}$ electrons and $60 \mathrm{MeV}$ protons.

\subsection{Irradiations to $232 \mathrm{MeV}$ Protons}

A single detector stack consisting of four layers of CR-39 PNTD and an array of LiF TLDs was assembled for each irradiation. Figure 3 illustrates the CR-39 PNTD/TLD stack. Each detector stack measured $4 \mathrm{~cm} \times 4 \mathrm{~cm}$ and was $\sim 1 \mathrm{~cm}$ in thickness. The four layers of CR-39, each $\sim 600 \mu \mathrm{m}$ in thickness, were separated by $\sim 8 \mu \mathrm{m}$ layers of Kimfoil polycarbonate film and a protective Lexan cover, $\sim 250 \mu \mathrm{m}$ in thickness, was placed at the front and back of the four layer CR-39 stack. A $3 \times 3$ array of TLDs was placed behind the CR-39 stack. Each TLD array consisted of five ${ }^{7}$ LiF TLDs, two uncovered ${ }^{6}$ LiF TLDs and two ${ }^{6} \mathrm{LiF}$ TLDs covered with Gd foil for the absorption of thermal neutrons. Each TLD measured $0.3 \mathrm{~cm} \times 0.3 \mathrm{~cm} \times 0.09 \mathrm{~cm}$. The TLDs were mounted in a $4 \mathrm{~cm} \times 4 \mathrm{~cm}$ acrylic holder and held in place by means of Teflon electrical tape. For cross-comparison tests a second set of a $3 \times 3$ array with TLDs provided by the JSC dosimetry group was also placed behind the ERI TLD array. Results from the JSC TLD exposures are not 
included in this report. An identifying label was affixed to each detector stack. Results from the five ${ }^{7} \mathrm{LiF}$ TLDs exposed in each detector stack were averaged into a single value of dose. The $232 \mathrm{MeV}$ proton irradiations are summarized in Table 3.

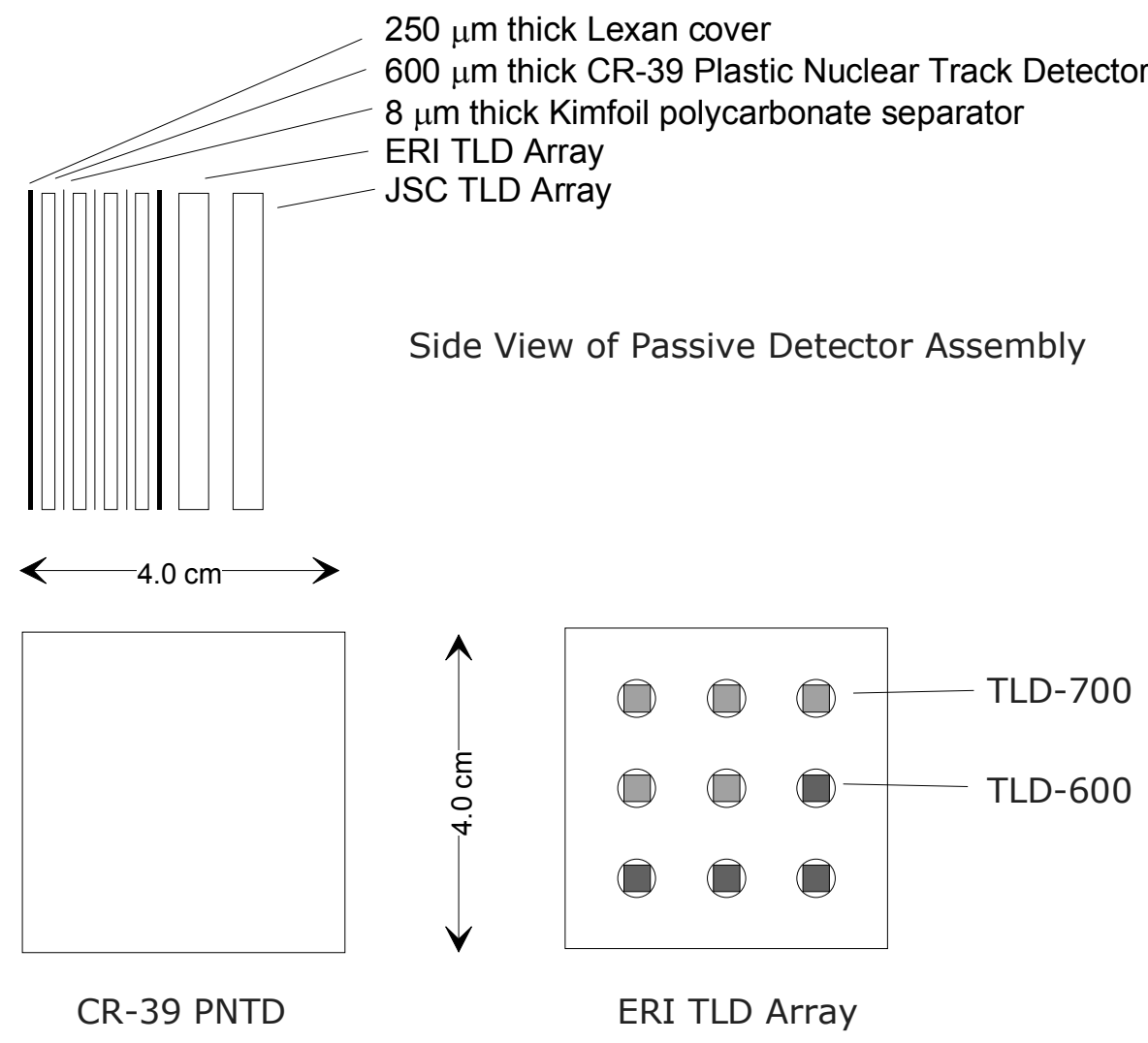

Figure 3. The CR-39 PNTD/TLD passive detector stack assembly used to measure LET spectra $\geq 5 \mathrm{keV} / \mu \mathrm{m}$, total dose, and dose equivalent within the tissue equivalent phantom inside of the EVA suits.

\subsubsection{Measurements at the Eye}

Detector stacks were exposed at the location of the phantom eye in both the EMU and Orlan-M helmets, and on the bare phantom head. The stacks were attached to the left eye of the phantom head by means of tape as shown in Figure 4. The helmet was exposed to the proton beam from the back so that the primary protons had to pass through the back of the helmet and through the head of the phantom before reaching the detector stack as illustrated in Figure 5. This geometry was used in order to maximize the number of target fragments produced and to measure fragment fluence in the eye from protons passing through the phantom head in the helmet. Figure 6 shows the EMU helmet during exposure of the detector stack at the phantom eye. Also, because of difficulty in aligning the beam in radiation gantry, so that the primary protons would pass through the helmet 
and into the detector from behind, it wasn't possible to expose the detector at multiple angles and only a $90^{\circ}$ angular alignment was used.

Table 3. High-energy proton (232 MeV) exposures and measurements at specified sites within the phantom inside of the EMU and Orlan-M space suits.

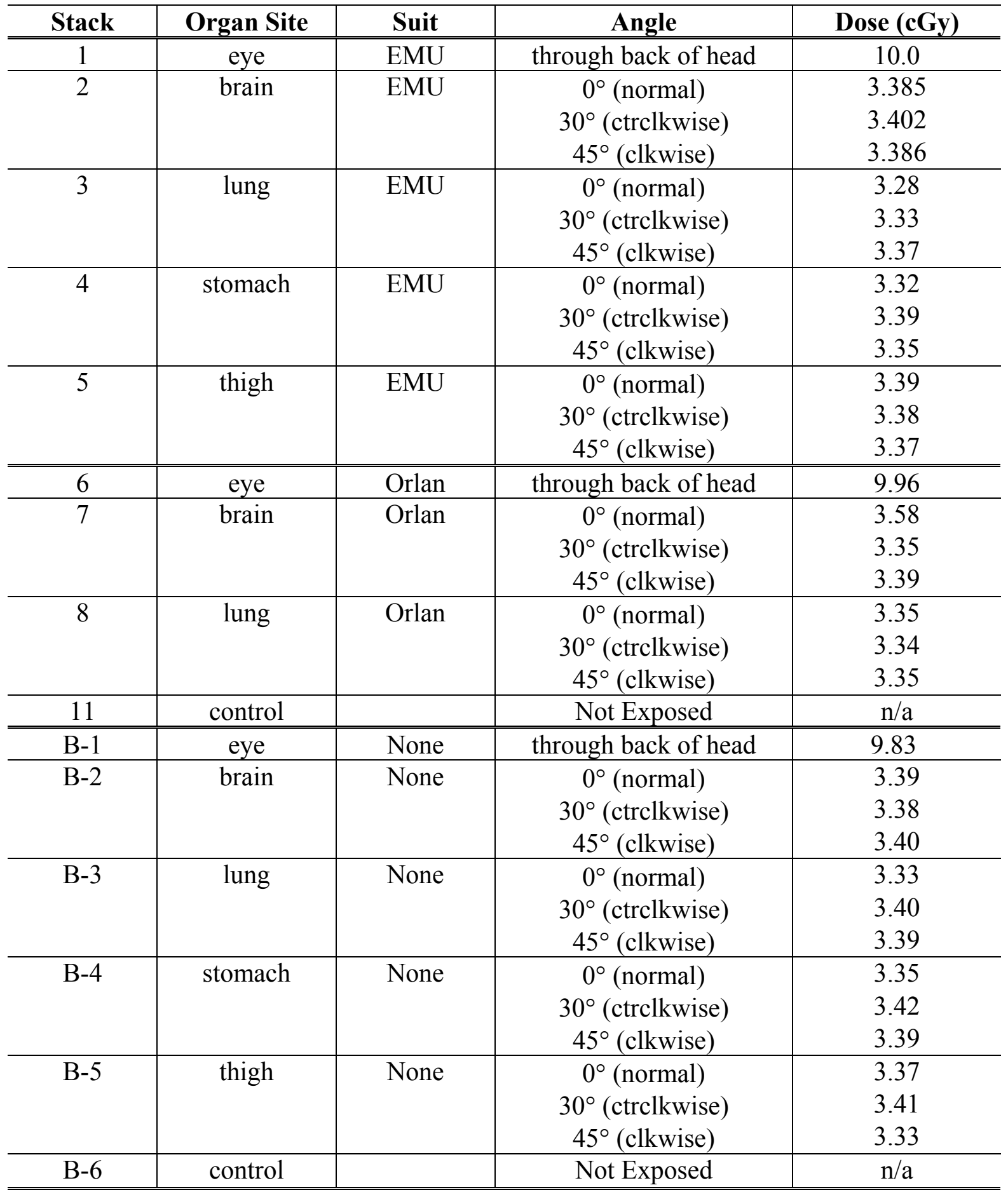




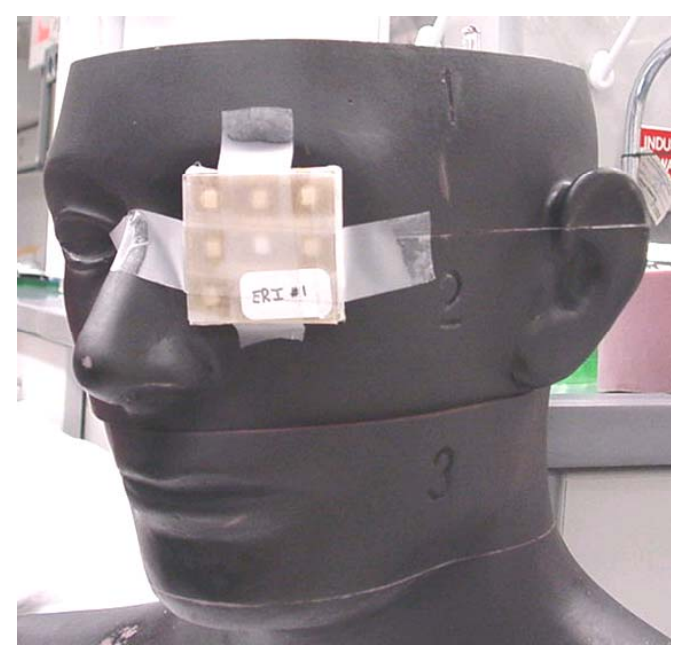

Figure 4. Detector array taped to the left eye of the phantom head in exposure configuration.

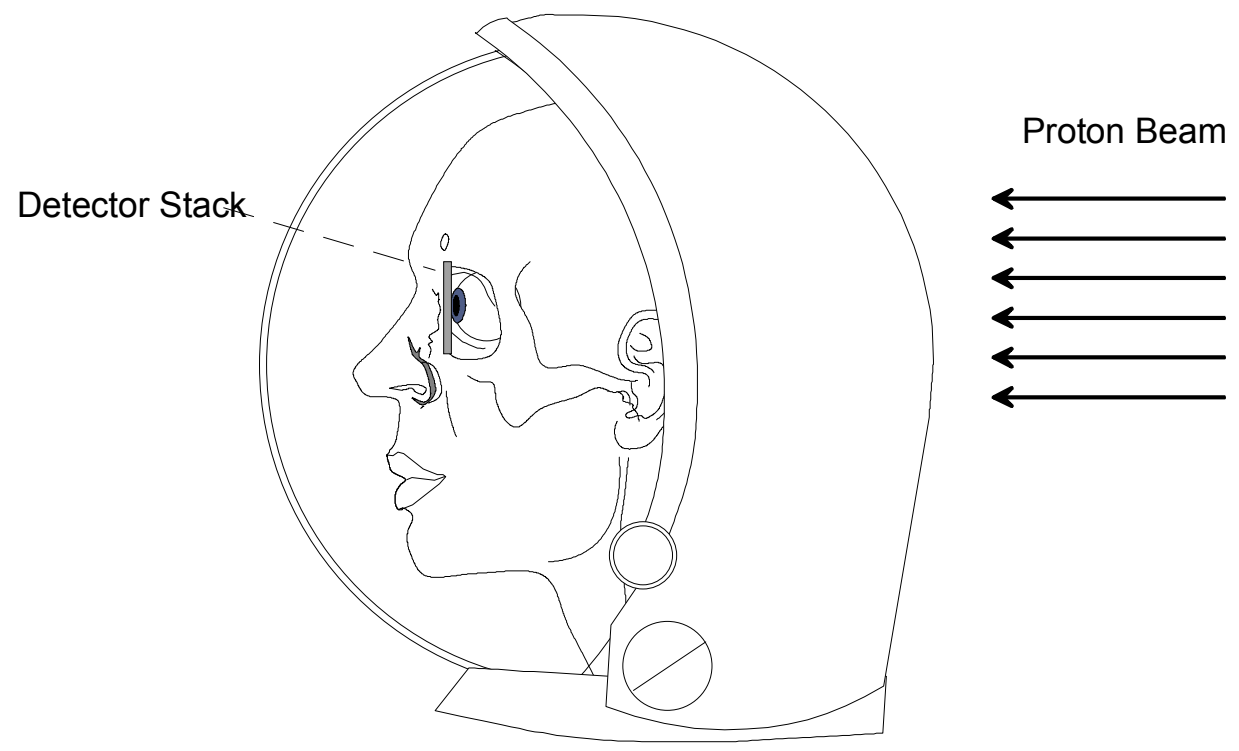

Figure 5. Geometry of the proton irradiation of the PNTD and TLD detector array positioned in front of the left eye of the phantom. 


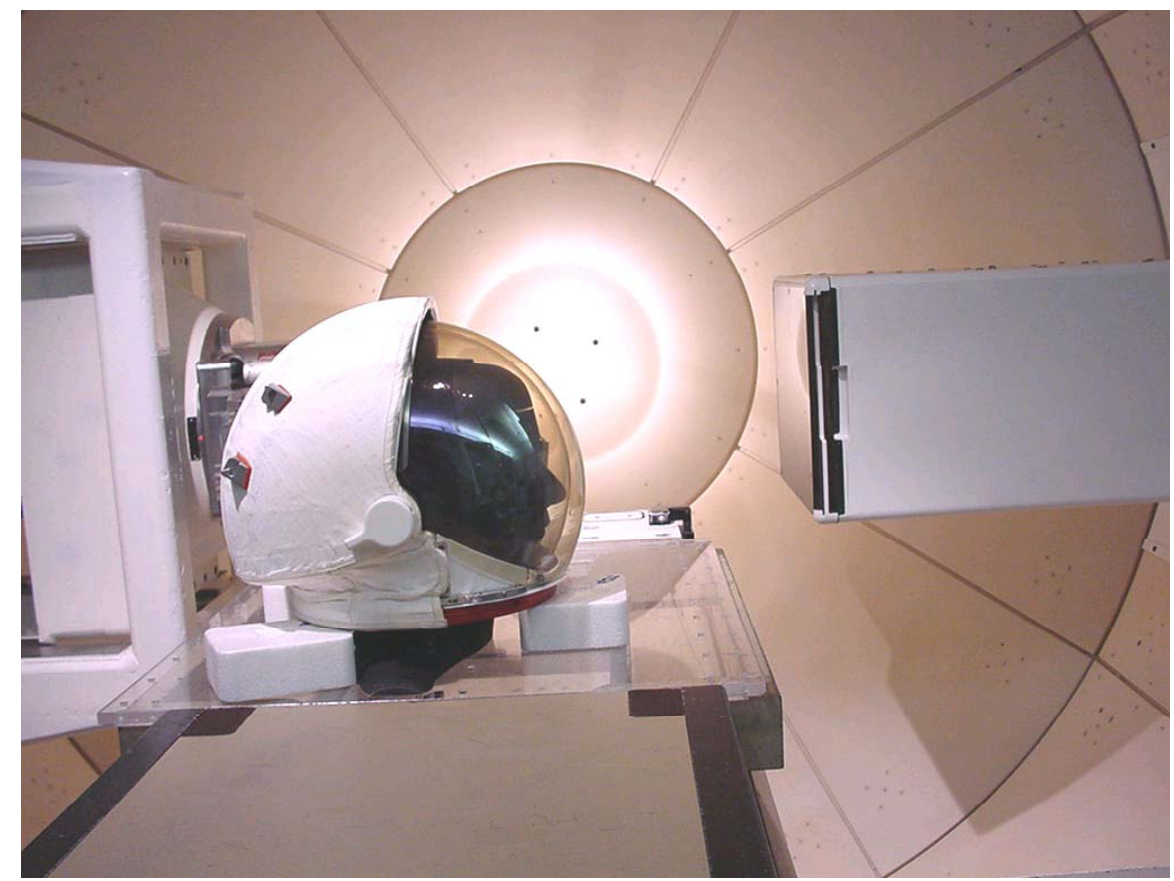

Figure 6. Proton irradiation set-up for the eye location in the EMU helmet. The beam enters the helmet from the back of the helmet.

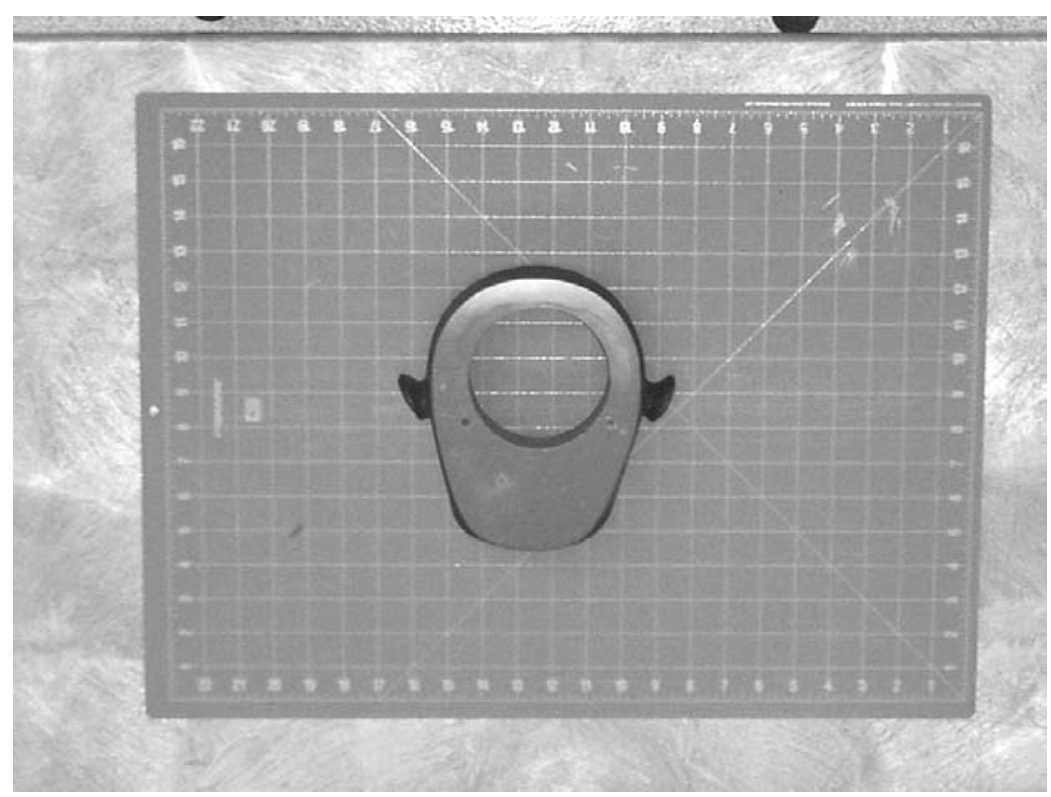

Figure 7. Horizontal cross section of the phantom head showing the opening for the cylindrical plug in which the detector stack was placed. The detector stack was oriented facing forward. 


\subsubsection{Measurements in the Brain}

Detector stacks were exposed to $232 \mathrm{MeV}$ protons at the center of the phantom's head at the location of the brain in the EMU and Orlan-M Helmets, and in the phantom head without helmet. The region of the phantom head that corresponds to the site of the brain was removed as shown in Figure 7. A cylindrical tissue-equivalent plug was cut in half and a slot to hold the detector stack was machined into the center of the plug. The detector surface was oriented perpendicular to the bilaterally symmetric axis of the phantom head. The head with helmet was exposed from the front at three angles to a total of $\sim 10$ cGy of protons as described in section 2.1.2.

\subsubsection{Measurements in the Lung}

Exposures of detector stacks at the site of the lungs were identical for the EMU and Orlan-M suits, and for the torso without suit. The exposure configuration was similar to that of the brain irradiations. The detector stack was placed inside a tissue-equivalent cylindrical plug, which was then inserted into the region of the phantom's left lung. Figure 8 shows the detector stack in the tissue equivalent plug at the site of the phantom lung. The exposure was made from the front of the suit in the case of both the EMU and Orlan-M suits. Total dose was $\sim 10 \mathrm{cGy}$ fractionated over exposures from three different angles as described in Section 2.1.2.

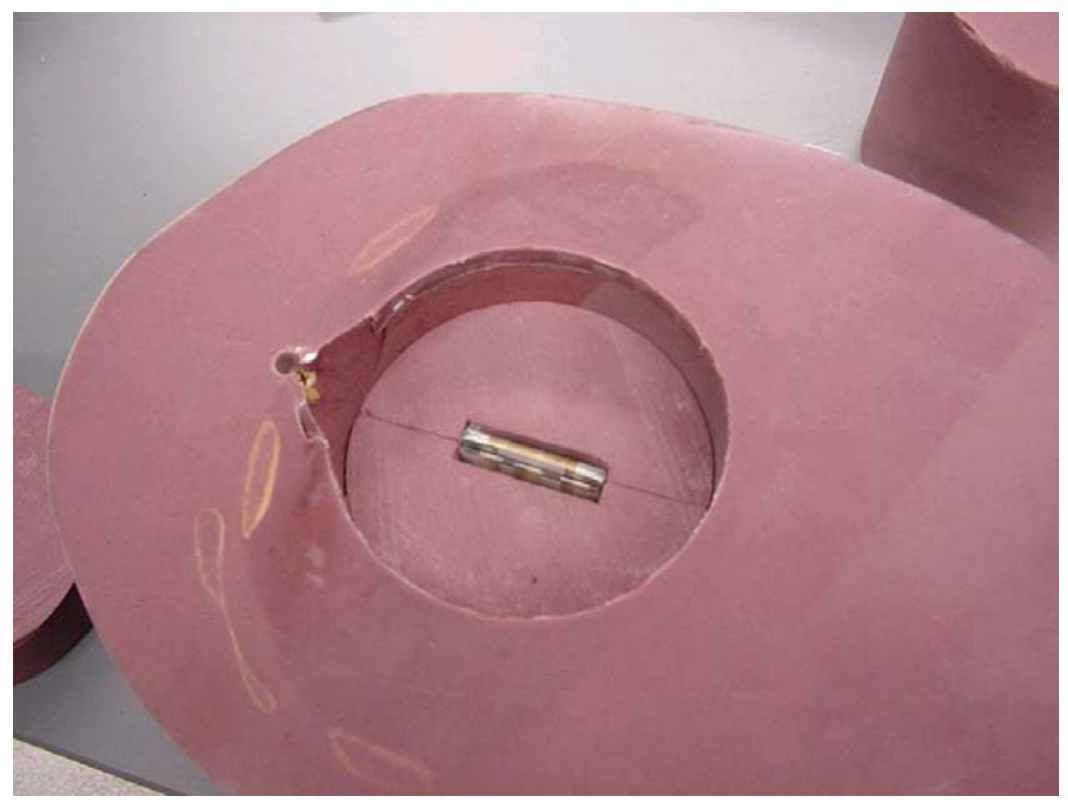

Figure 8. Detector stack as placed in the left lung of the phantom. The detector stack faced forward during the irradiation. 


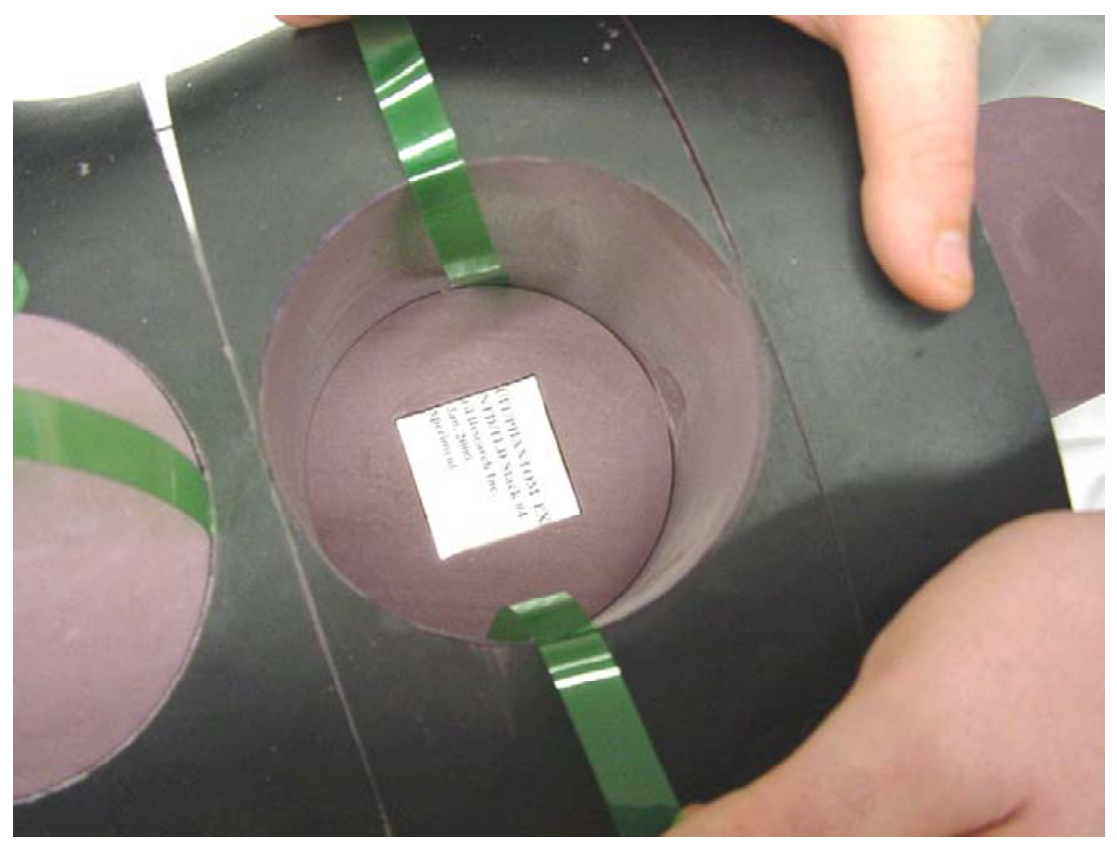

Figure 9. Detector stack placed at the back of the stomach cavity and up against the front of the spine. At the left of the photograph the cylindrical plug at the site of the phantom abdomen can also be seen.

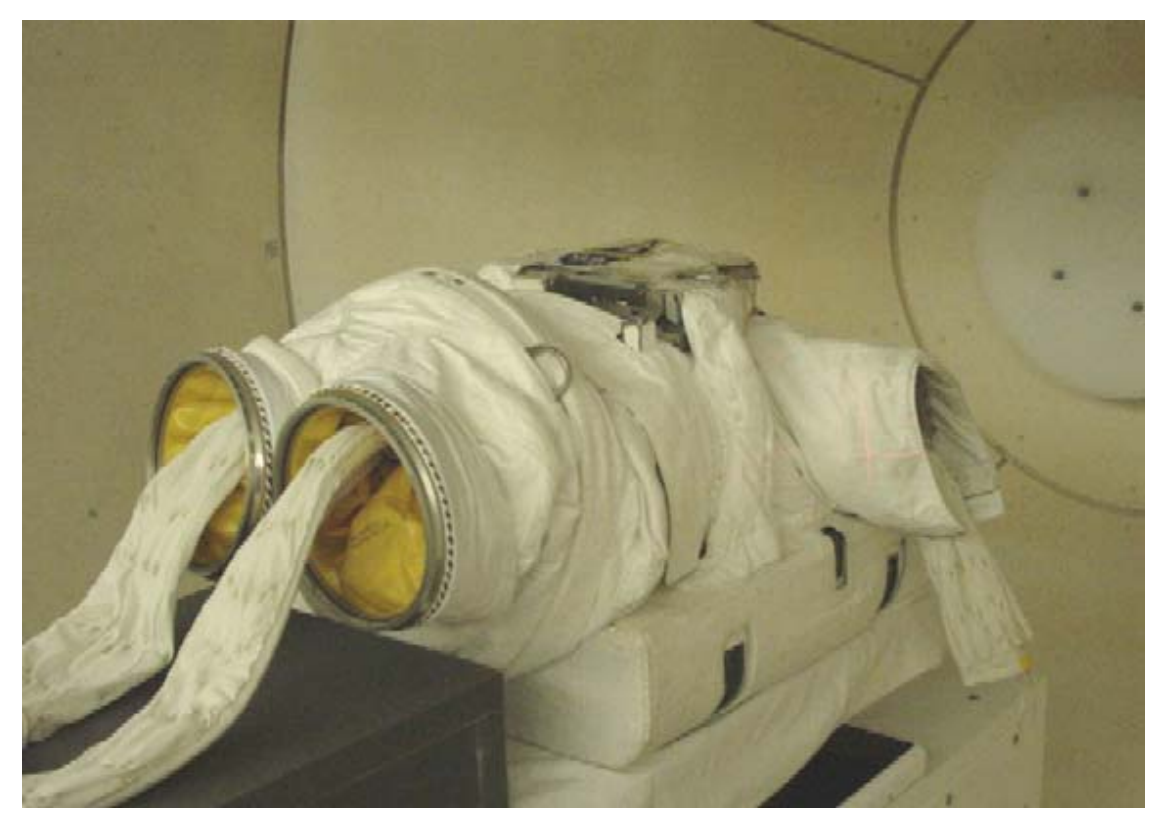

Figure 10. Torso portion of the EMU suit during exposure of stomach detector stack. The beam entered the suit from above. 


\subsubsection{Measurements in the Stomach}

Detector stacks were exposed at the site of the phantom stomach only for the EMU suit and for the bare phantom. Due to the fact that the Orlan-M suit is not modular as in the case of the EMU suit, it was not possible to irradiate detector stack in the stomach in front of the beam while inside the Orlan-M suit. In addition the metal support attached to the Orlan-M suit to carry it on a dolly was in the way for the radiation beam trajectory.

The stomach of the phantom possesses a cylindrical cavity extending from the anterior of the body until just in front of the spinal column. The detector stack was placed at the deepest position inside this cylindrical cavity up against the spinal column as illustrated in Figure 9. Cylinders of tissue equivalent plastic material then filled out the stomach and the phantom torso was placed inside the EMU suit. Figure 10 shows the torso of the EMU in exposure configuration during the irradiation of the stomach detector stack. A total of $\sim 10 \mathrm{cGy}$ of $232 \mathrm{MeV}$ protons was delivered in three equal exposures at $90^{\circ}, 45^{\circ}$ and $60^{\circ}$ relative to the plane of the detectors as explained in Section 2.1.2.

\subsubsection{Measurements in the Thigh}

Detector stacks were exposed at the site of the left thigh, directly in front of the femur of the phantom in the phantom alone and while wearing the EMU suit. As with the stomach irradiation, it was not possible to properly align the thigh detector stack with the beam while inside the Orlan-M suit and this exposure was not made. Figure 11 shows the phantom thigh, detector stack, and the cylindrical plug placed in front of the detector stack during the exposures. As with most of the other exposures, the $\sim 10$ cGy dose was distributed between exposures made at three different angles.

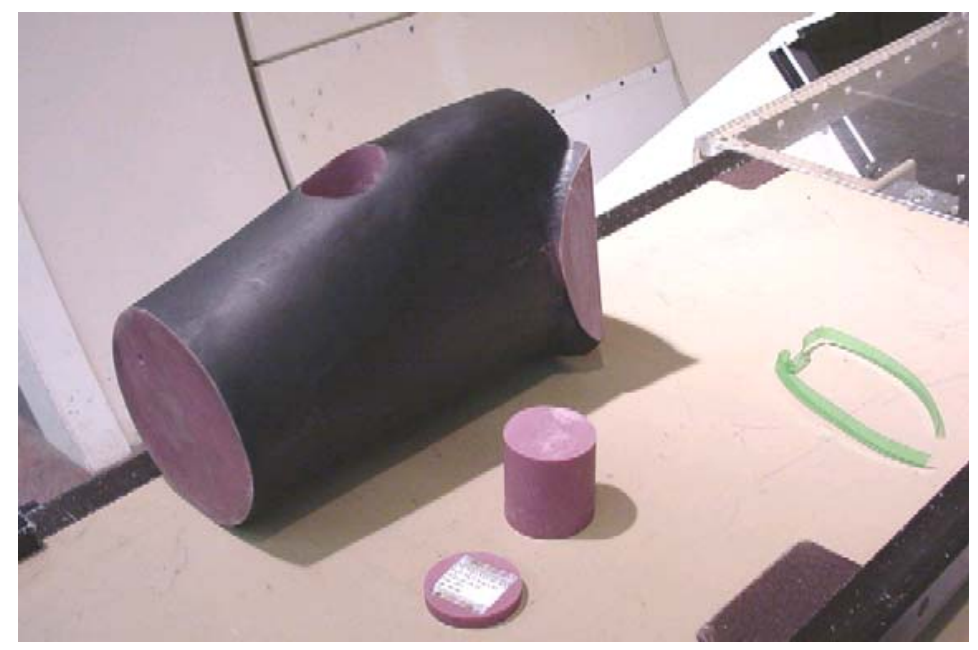

Figure 11. A part of the phantom's right thigh, detector stack, and tissue equivalent plug used in making irradiations of the thigh location while inside the EMU suit. 


\section{RESULTS AND DISCUSSION}

\subsection{Doses from $6 \mathrm{MeV}$ Electron Irradiations}

The dose/depth measurements made inside the EVA suits for the $6 \mathrm{MeV}$ electron beam exposures are shown in Figure 12. The depth in water presented in Figures 12 was derived from depth in $\mathrm{LiF}$ based on the relative ranges of electrons in the two media. Range-Energy tables show that for $6 \mathrm{MeV}$ electrons the range in water is a factor of 0.808 times the range in ${ }^{7} \mathrm{LiF}$ (in units of $\mathrm{g} / \mathrm{cm}^{2}$ ) [5].

All of the measured doses were considerably less than the incident $10 \mathrm{cGy}$, illustrating significant attenuation in the electron flux within the mass of the two helmets and the two suit swatches. The Orlan-M helmet doses were least while doses from the EMU helmet were intermediate, indicating that the eye locations in the helmets were more heavily shielded than the other suit locations. A gradual increase in dose with depth followed by a gradual decrease with further depth is seen for all four measurements. The depth of maximum dose was $0.34 \mathrm{~g} / \mathrm{cm}^{2}$ for the EMU helmet, $0.46 \mathrm{~g} / \mathrm{cm}^{2}$ for EMU suit swatch and $0.65 \mathrm{~g} / \mathrm{cm}^{2}$ for Orlan-M suit swatch. The dose profile behind the Orlan-M helmet has a broad maximum from about 0.24 to $0.65 \mathrm{~g} / \mathrm{cm}^{2}$. The maximum was also relatively less in the Orlan-M helmet than behind the other materials, yielding a flatter dose distribution. The peaks in the EMU suit swatch and Orlan-M suit swatch may be due to the scatter of electrons off of tubing used to circulate coolant within the suit.

\section{2 $60 \mathrm{MeV}$ Proton Irradiations}

Dose/depth distributions inside the EVA helmets and behind the suit swatches for the $60 \mathrm{MeV}$ proton exposures are shown in Figure 13. The depth in water presented in Figure 13 was derived from depth in $\mathrm{LiF}$ based on the relative range of protons in $\mathrm{LiF}$ and $\mathrm{H}_{2} \mathrm{O}$. Range-Energy tables show that $60 \mathrm{MeV}$ proton range in water is a factor of 0.7966 times the range in ${ }^{7} \mathrm{LiF}$ (in units of $\mathrm{g} / \mathrm{cm}^{2}$ ) [6].

All of the measured doses are higher than the corresponding incident dose, indicating that significant slowing of the proton beams occurred in passage through the suit materials. Doses immediately behind the suit vary from 11 to $14 \mathrm{cGy}$. The dose/depth profiles are characterized by gradual increases in dose through about $1 \mathrm{~g} / \mathrm{cm}^{2}$, then steeper increases toward the Bragg peak maximum. Only the Orlan-M helmet profile seems to show a decrease from the Bragg peak at the last TLD location in the stack. The dose distribution at the eye/helmet location in the Orlan-M suit is (as in the electron beam irradiation) quantitatively different than that measured for the other three materials. 


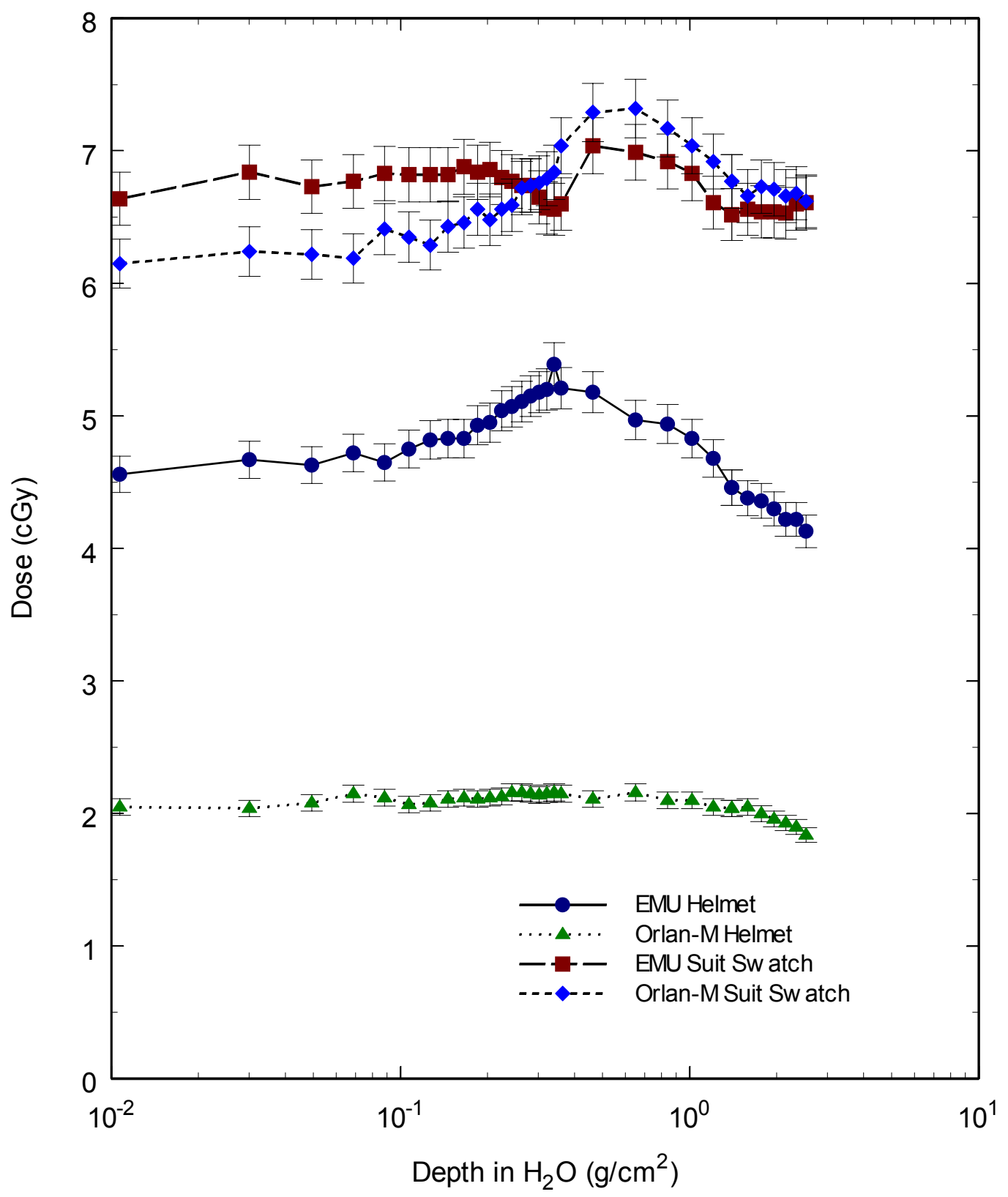

Figure 12. Dose as a function of depth in water measured using TLDs exposed behind the EMU and Orlan-M helmets and behind swatches of the EMU and Orlan-M suit material. 


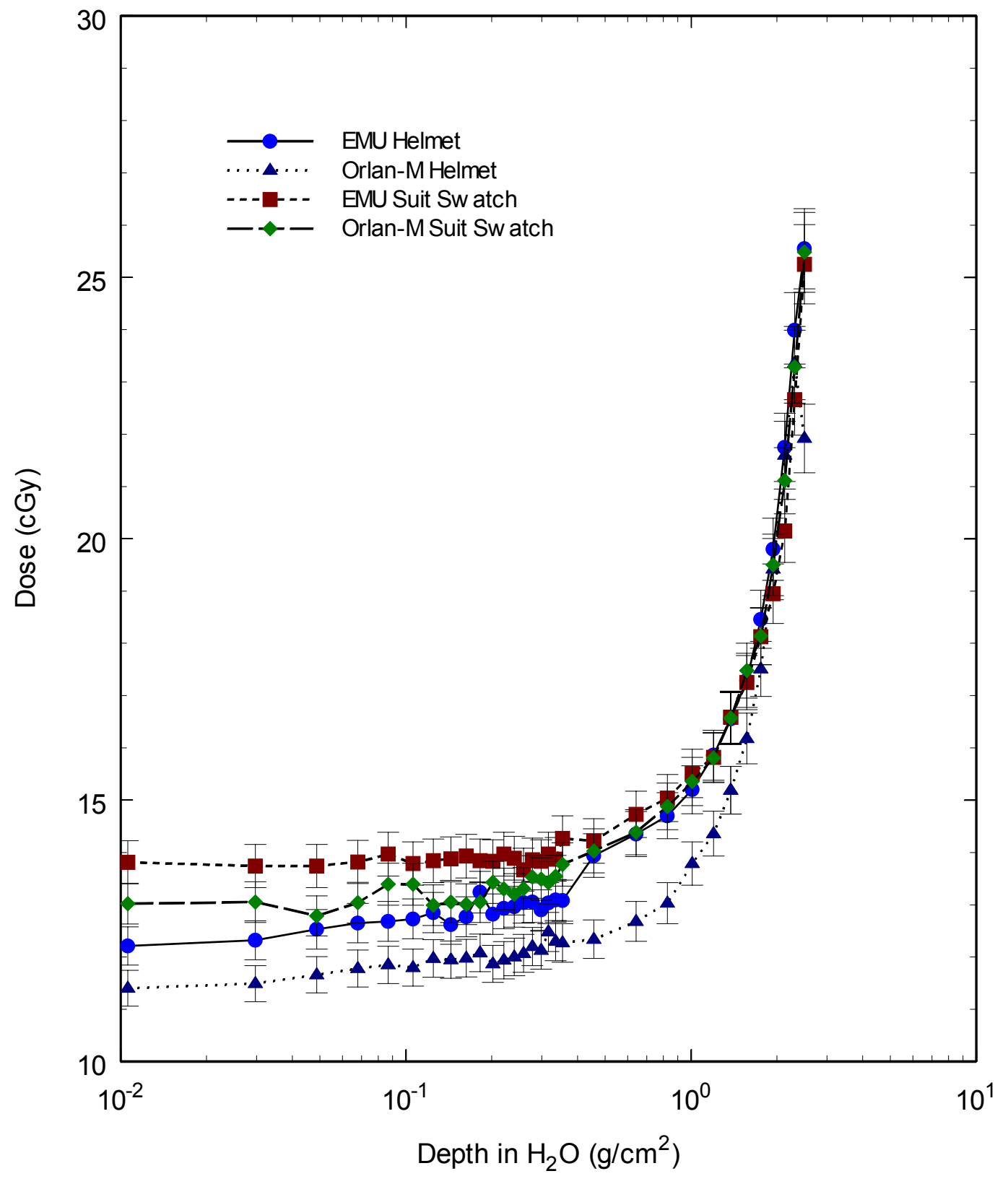

Figure 13. Dose as a function of depth in water measured using TLDs exposed to $60 \mathrm{MeV}$ protons behind the EMU and Orlan-M helmets and behind swatches of the EMU and Orlan-M suit materials. 


\subsection{Results from 232 MeV Proton Irradiations}

\section{$\underline{\text { 3.3.1 Doses from 232 MeV Proton Irradiations }}$}

Results from the TLDs exposed to $232 \mathrm{MeV}$ protons inside the phantom in the EMU and Orlan-M suits are presented in Table 4. The ion chamber doses reported in Table 4 were made for the pristine beam before it passed through any material. The smaller doses measured by TLDs reflect attenuation of the beam as it passed through the bulk of the suit and the phantom. Differences between the doses measured by TLDs and by the beam-line ion chamber may also reflect the alignment of the detectors during the irradiations. Since the detector stack was placed inside the phantom, which itself was inside one of the suits, alignment of the detector stack relative to the beam line often had to be estimated.

Doses measured with TLD-700 show that for head exposures (eye/brain) the measured doses were considerably less than the incident doses. This was most likely due to beam attenuation. Body exposures (lung/stomach/thigh) showed that measured organ doses were only moderately lower than corresponding incident doses.

Table 4. Absorbed dose measurements with TLDs (passive detectors) and beam-line ionization chamber doses for $232 \mathrm{MeV}$ proton irradiations at selected locations in the phantom inside the EMU and Orlan-M suits.

\begin{tabular}{c|c|c|c|c|c}
\hline \multirow{2}{*}{ Location } & \multirow{2}{*}{ Suit } & \multirow{2}{*}{$\begin{array}{c}\text { on Chamber } \\
\text { Dose }(\mathrm{cGy})\end{array}$} & \multicolumn{3}{|c}{ TLD Absorbed Dose (cGy) } \\
\cline { 4 - 6 } & & & ${ }^{7} \mathrm{LiF}$ & ${ }^{6} \mathrm{LiF}$ & ${ }^{6} \mathrm{LiF}(\mathrm{Gd})$ \\
\hline \hline Eye & EMU & 10.00 & $8.97 \pm 0.27$ & $9.23 \pm 0.28$ & $9.34 \pm 0.28$ \\
\hline Brain & EMU & 10.17 & $8.49 \pm 0.25$ & $8.41 \pm 0.25$ & $8.80 \pm 0.26$ \\
\hline Lung & EMU & 9.98 & $9.61 \pm 0.29$ & $10.38 \pm 0.31$ & 10.870 .33 \\
\hline Stomach & EMU & 10.06 & $10.03 \pm 0.30$ & $11.47 \pm 0.34$ & $11.61 \pm 0.35$ \\
\hline Thigh & EMU & 10.14 & $10.81 \pm 0.32$ & $10.96 \pm 0.33$ & $10.58 \pm 0.32$ \\
\hline Eye & Orlan-M & 9.96 & $8.47 \pm 0.25$ & $8.59 \pm 0.26$ & $9.00 \pm 0.27$ \\
\hline Brain & Orlan-M & 10.32 & $9.46 \pm 0.28$ & $\mathrm{n} / \mathrm{a}$ & $\mathrm{n} / \mathrm{a}$ \\
\hline Lung & Orlan-M & 10.04 & $9.71 \pm 0.29$ & $\mathrm{n} / \mathrm{a}$ & $\mathrm{n} / \mathrm{a}$ \\
\hline
\end{tabular}

Results from the comparison of TLD-600 $\left({ }^{6} \mathrm{LiF}\right)$ and TLD-700 $\left({ }^{7} \mathrm{LiF}\right)$ dose measurements indicate that there was no appreciable contribution to dose from thermal and epithermal neutrons. Only in the case of the lung and stomach irradiations were the doses measured by TLD-600 significantly larger than doses measured by TLD-700. In all other cases, dose measurements from the two types of TLD agreed within experimental uncertainty. The larger doses measured in TLD-600 over TLD-700 in the lung and stomach may be due to an increase in the fluence of low energy neutrons produced by the tissue equivalent material surrounding the detectors. In all cases, the TLD-600 dose 
measurements made behind Gd absorber agreed with TLD-600 measurements made with no absorber within the limits of experimental uncertainty, indicating that there was no appreciable contribution to dose from thermal neutrons.

\subsubsection{LET Spectra, Total Dose and Dose Equivalent Measurements}

The integral LET fluence, dose, and dose equivalent spectra measured using CR-39 PNTDs was normalized to the incident primary proton fluence determined from dose measurements made by the in-line dosimetry ion chamber and corresponding to a total dose of $\sim 10$ cGy of $232 \mathrm{MeV}$ energy beam (see Table 4). Normalization to incident proton fluence permits measurements made during separate irradiations to be directly compared. The ICRP-60 definition of quality factor was used in determining dose equivalent [7]. The error bars associated with the measurements made in the Orlan-M suit and in the bare phantom are significantly larger than those for the EMU measurements. This is a result of the smaller sample size measured in the Orlan-M and bare phantom detectors, rather than any inherent limitation in the method.

While the LET spectra $\geq 5 \mathrm{keV} / \mu \mathrm{m}$, and the total dose, dose equivalent, and average quality factor measurements derived from the LET spectra, reflect the importance of high-LET target fragmentation, these measurements do not completely quantify the total target fragmentation contribution. This is due to limitations inherent in the optical microscopy method used to analyze the CR-39 PNTDs. The minimum range of the measurable target fragments are on the order of the thickness of bulk CR-39 detector removed by chemical processing. For optical microscopy analysis of CR-39 PNTD, this is $\sim 8 \mu \mathrm{m}$. Removing less than $8 \mu \mathrm{m}$ of material during chemical processing results in tracks that are too small to accurately measure using optical methods. This means that target fragments of range $<8 \mu \mathrm{m}$ are not measured and their contribution to dose, dose equivalent, and mean quality factor must be neglected.

\subsubsection{Eye Exposures}

Integral LET fluence, dose and dose equivalent spectra measured in detector arrays exposed in front of the phantom eye by protons passing through the back of the phantom head are shown in Figure 14. The fluence spectra for all three detectors lie fairly close to one another at lower LET $(<100 \mathrm{keV} / \mu \mathrm{m})$. Differences between the Orlan-M helmet spectrum and the other two spectra in the LET region below $30 \mathrm{keV} / \mu \mathrm{m}$ most likely result from differences in the scanning efficiency amongst the microscopists who read out the detectors. There was a larger number of high LET events $(>200 \mathrm{keV} / \mu \mathrm{m})$ measured in the EMU eye detector as compared to the other two eye detectors which results in the dose and dose equivalent curves measured in the EMU helmet lying well above those measured for the bare phantom. These high LET events are most likely recoil heavy nuclei. 
Table 5 lists the total dose corrected for high-LET particle contribution, dose equivalent and average quality factor determined from combined CR-39 PNTD and TLD measurements. Also shown in Table 5 are the dose and dose equivalents from charged particles of LET $\geq 5 \mathrm{keV} / \mu \mathrm{m}$, assumed to be target fragments, and their relative contributions to total dose and dose equivalent. Both dose and dose equivalent are lower in the two helmets-by $22 \%$ and $27 \%$, respectively, in dose and $14 \%$ and $25 \%$, respectively, in dose equivalent - than for the bare phantom head, illustrating the attenuation of the beam by the shielding provided by the helmets. Furthermore, it appears that the Orlan-M helmet provides more shielding than does the EMU helmet.

The contribution of target fragments to total dose at the eye was $4.1 \%$ for the bare phantom head, $4.6 \%$ for the Orlan-M helmet, and 6.2\% for the EMU helmet. Similarly, the contribution of target fragments to total dose equivalent at the eye ranged from $32 \%$ for the bare phantom and $34 \%$ for the Orlan-M helmet up to $40 \%$ for the EMU helmet. From these results it appears that the Orlan-M helmet is not a significant source of target fragments. The EMU helmet, on the other hand, produces a sizable number of target fragments in addition to those created in the head of the phantom. This result is further borne out in the average quality factor measured for the eye exposures. Average quality factor for the bare head and the Orlan-M helmet are nearly the same at $1.41 \pm 0.17$ and $1.44 \pm 0.17$, respectively. The average quality factor measured inside the EMU helmet is significantly higher at $1.57 \pm 0.07$. The larger number of high LET events measured in the EMU helmet detector is principally responsible for this larger average quality factor.

Table 5. Total Dose, Dose Equivalent, and Mean Quality Factor from $\sim 10 \mathrm{cGy}, 232 \mathrm{MeV}$ proton irradiations measured using CR-39 PNTDs and LiF TLDs at the phantom eye for the bare phantom head, phantom head inside the EMU helmet and phantom head inside the Orlan-M helmet.

\begin{tabular}{l|c|c|c}
\hline Helmet & None & EMU & Orlan-M \\
\hline \hline Total Dose $\left(\mathrm{cGy} /\right.$ proton $\left.\times 10^{-8}\right)$ & $7.55 \pm 0.58$ & $5.90 \pm 0.19$ & $5.53 \pm 0.42$ \\
\hline Change in Dose due to Helmet & $\mathrm{n} / \mathrm{a}$ & $-22 \%$ & $-27 \%$ \\
\hline Dose $_{\mathrm{TLD}}\left(\mathrm{cGy} /\right.$ proton $\left.\times 10^{-8}\right)$ & $7.24 \pm 0.41$ & $5.54 \pm 0.17$ & $5.28 \pm 0.29$ \\
\hline Dose $_{\mathrm{PNTD}}\left(\mathrm{cGy} /\right.$ proton $\left.\times 10^{-8}\right)$ & $0.31 \pm 0.02$ & $0.37 \pm 0.01$ & $0.25 \pm 0.01$ \\
\hline Target Fragmentation Dose Contribution & $4.1 \%$ & $6.2 \%$ & $4.6 \%$ \\
\hline Total Dose Equivalent $\left(\mathrm{cSv} /\right.$ proton $\left.\times 10^{-8}\right)$ & $10.70 \pm 1.01$ & $9.25 \pm 0.29$ & $7.99 \pm 0.75$ \\
\hline Change in Dose Equivalent due to Helmet & $\mathrm{n} / \mathrm{a}$ & $-14 \%$ & $-25 \%$ \\
\hline Dose Equivalent & & & \\
\hline Target $\left(\mathrm{cSv} /\right.$ proton $\left.\times 10^{-8}\right)$ & $3.42 \pm 0.26$ & $3.71 \pm 0.01$ & $2.71 \pm 0.20$ \\
$\begin{array}{l}\text { Dose Equivalent Contribution } \\
\text { Average Quality Factor }\end{array}$ & $32 \%$ & $40 \%$ & $34 \%$ \\
\hline $\begin{array}{l}\text { Change in Average Quality Factor } \\
\text { due to Helmet }\end{array}$ & $1.41 \pm 0.17$ & $1.57 \pm 0.07$ & $1.44 \pm 0.17$ \\
\hline
\end{tabular}


Eril Research, Inc.
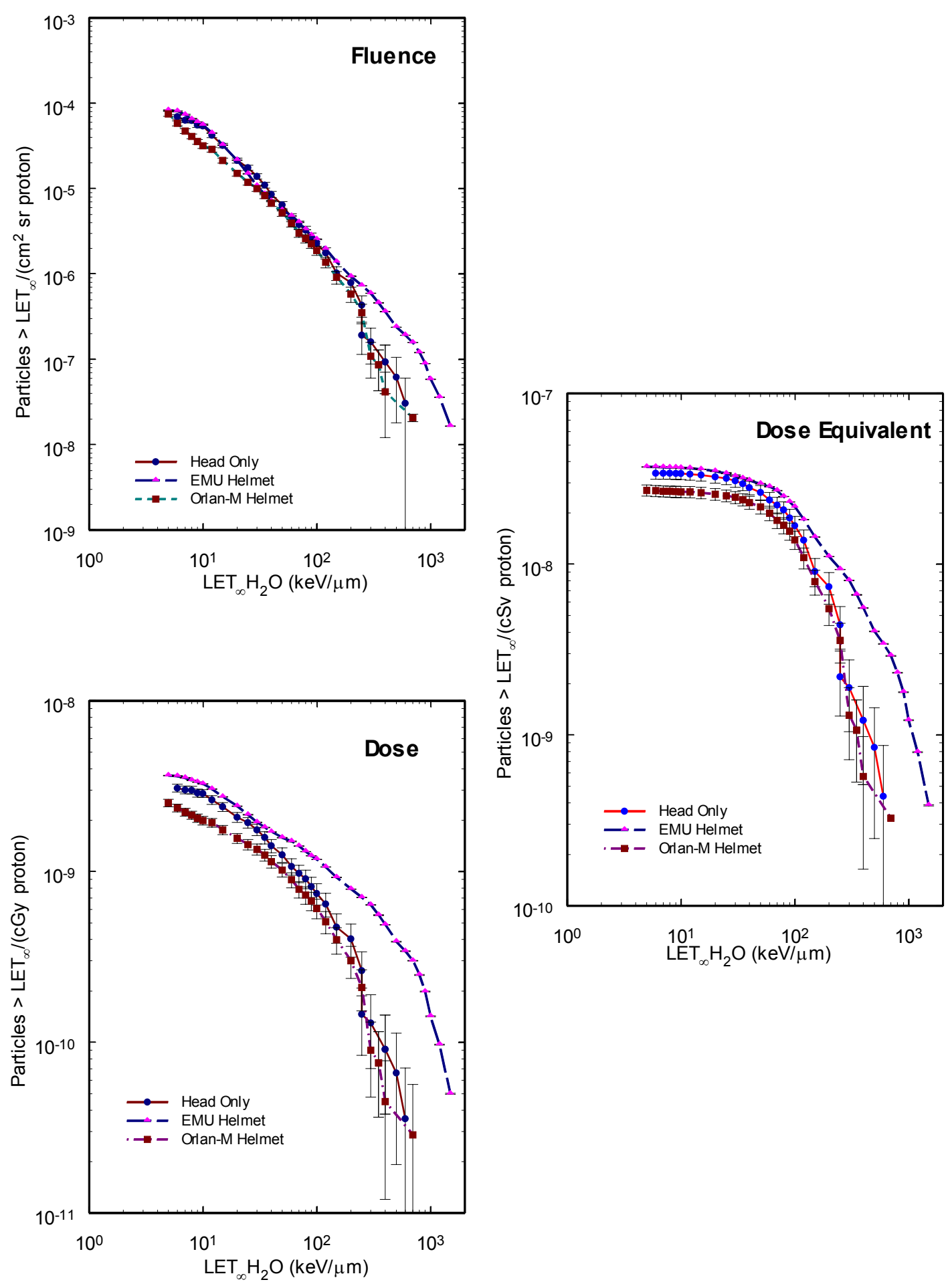

Figure 14. Integral LET Fluence, Dose and Dose Equivalent Spectra from $232 \mathrm{MeV}$ proton irradiations measured using CR-39 PNTDs at the phantom eye. 


\subsubsection{Brain Exposures}

Integral LET fluence, dose and dose equivalent spectra measured in CR-39 PNTDs positioned in the center of the phantom head are shown in Figure 15. As in the eye exposures, the three fluence spectra lie fairly close to one another at lower LET $(<100 \mathrm{keV} / \mu \mathrm{m})$. Again, differences between the three spectra in the LET region below $30 \mathrm{keV} / \mu \mathrm{m}$ probably arise from differences in the scanning efficiency of individual microscopists. For LET above $100 \mathrm{keV} / \mu \mathrm{m}$, both the Orlan-M and EMU spectra lie above that measured inside the bare phantom head. This difference is most notable in the dose and dose equivalent spectra.

Total dose corrected for high-LET particle contribution, dose equivalent and average quality factor determined from combined CR-39 PNTD and TLD measurements are given in Table 6 . Table 6 also presents the dose and dose equivalents from target fragments, and the relative contributions to total dose and dose equivalent from target fragments. Total dose is $21 \%$ lower in the center of the brain in the EMU helmet and $13 \%$ lower in the Orlan-M helmet than in the bare phantom head, indicating that the helmets are attenuating some of the dose. However, while the dose equivalent is $8 \%$ lower in the EMU helmet, it is nearly identical in both the Orlan-M helmet and the bare phantom. The contribution from target fragmentation to total dose at the center of the brain was 3.5\% for the bare phantom head, 5.9\% inside the EMU helmet, and 6.0\% inside the Orlan-M helmet. The contribution of target fragments to total dose equivalent at the brain site the was $33 \%$ inside the bare phantom head, $44 \%$ inside the EMU helmet, and $43 \%$ inside the Orlan-M helmet.

Table 6. Total Dose, Dose Equivalent, and Mean Quality Factor from $\sim 10 \mathrm{cGy}, 232 \mathrm{MeV}$ proton irradiations measured using CR-39 PNTDs and LiF TLDs in the center of the phantom brain for the bare phantom head, phantom head inside the EMU helmet, and phantom head inside the Orlan-M helmet.

\begin{tabular}{l|c|c|c}
\hline Helmet & None & EMU & Orlan-M \\
\hline \hline Total Dose $\left(\mathrm{cGy} /\right.$ proton $\left.\times 10^{-8}\right)$ & $6.92 \pm 0.42$ & $5.49 \pm 0.17$ & $6.04 \pm 0.19$ \\
\hline Change in Dose due to Helmet & $\mathrm{n} / \mathrm{a}$ & $-21 \%$ & $-13 \%$ \\
\hline Dose $_{\mathrm{TLD}}\left(\mathrm{cGy} /\right.$ proton $\left.\times 10^{-8}\right)$ & $6.69 \pm 0.31$ & $5.14 \pm 0.16$ & $5.68 \pm 0.18$ \\
\hline Dose $_{\text {PNTD* }}\left(\mathrm{cGy} /\right.$ proton $\left.\times 10^{-8}\right)$ & $0.24 \pm 0.01$ & $0.32 \pm 0.01$ & $0.36 \pm 0.01$ \\
\hline Target Fragmentation Dose Contribution & $3.5 \%$ & $5.9 \%$ & $6.0 \%$ \\
\hline Total Dose Equivalent $\left(\mathrm{cSv} /\right.$ proton $\left.\times 10^{-8}\right)$ & $9.94 \pm 0.68$ & $9.15 \pm 0.28$ & $9.99 \pm 0.35$ \\
\hline Change in Dose Equivalent due to Helmet & $\mathrm{n} / \mathrm{a}$ & $-8 \%$ & $0.5 \%$ \\
\hline Dose Equivalent & $3.25 \pm 0.17$ & $4.01 \pm 0.01$ & $4.31 \pm 0.43$ \\
\hline $\begin{array}{l}\text { Target Fragmentation }\left(\mathrm{cSv} / \text { proton } \times 10^{-8}\right) \\
\text { Dose Equivalent Contribution }\end{array}$ & $33 \%$ & $44 \%$ & $43 \%$ \\
\hline Average Quality Factor & $1.43 \pm 0.13$ & $1.66 \pm 0.07$ & $1.65 \pm 0.08$ \\
\hline $\begin{array}{l}\text { Change in Average Quality Factor } \\
\text { due to Helmet }\end{array}$ & $\mathrm{n} / \mathrm{a}$ & $14 \%$ & $13 \%$ \\
\hline
\end{tabular}



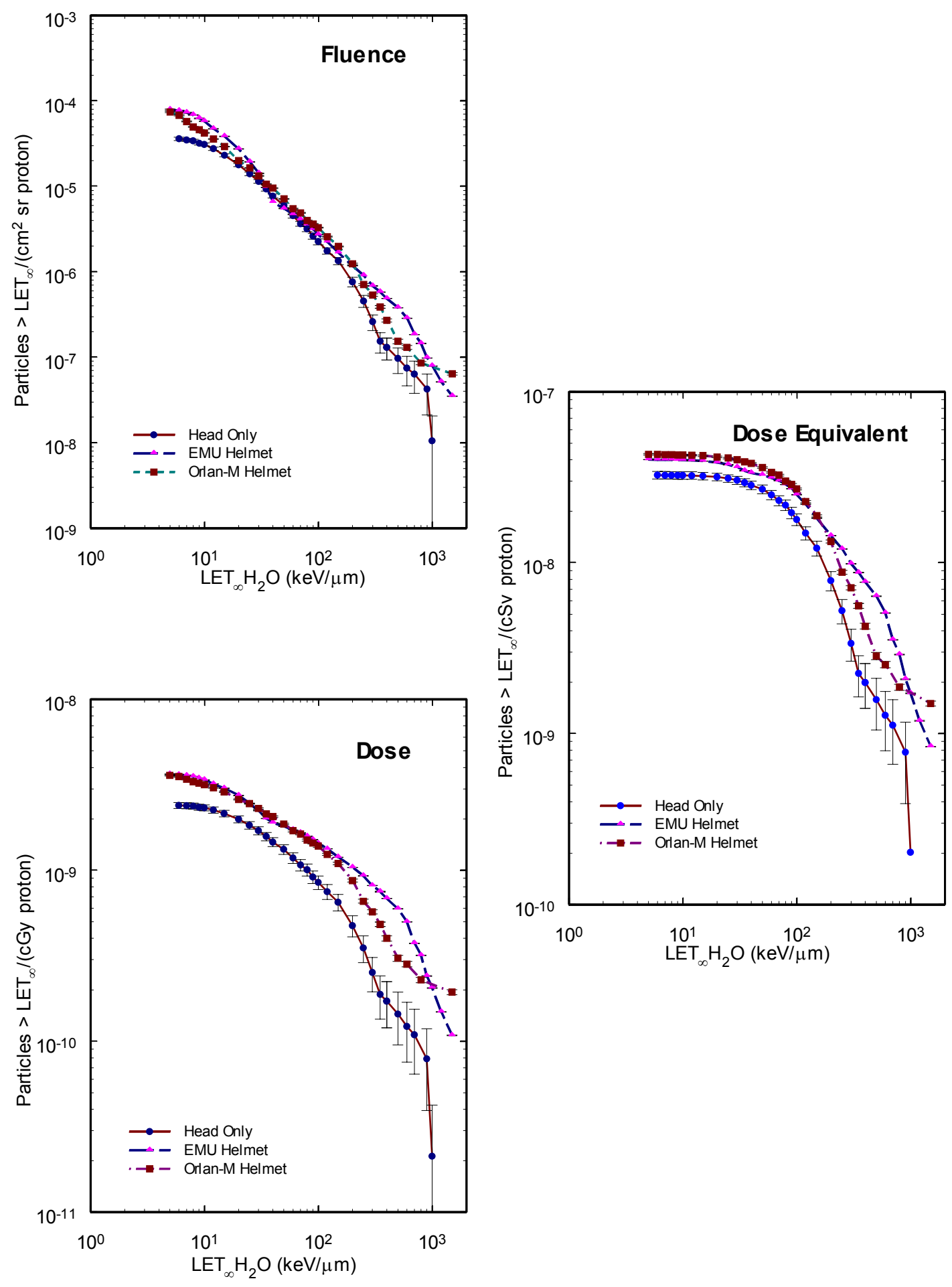

Figure 15. Integral LET Fluence, Dose and Dose Equivalent Spectra from $232 \mathrm{MeV}$ proton irradiations measured using CR-39 PNTDs in the phantom brain. 
Average quality factor for the bare head was $1.43 \pm 0.13$, in close agreement with that measured at the eye location for the bare head. Average quality factor for the EMU helmet and the Orlan-M helmet are nearly the same at $1.66 \pm 0.07$ and $1.65 \pm 0.08$, respectively. Thus, both the EMU helmet and Orlan-M helmet are significant sources of target fragments, adding to those produced in the phantom head. Unlike the eye exposures, where the proton beam passed through the back of the helmet and through the head at a single angle (see Figure 5), the brain exposures were made at three angles (Figure 1) and passed through the helmet visors.

\subsubsection{Lung Exposures}

Figure 16 shows the integral LET fluence spectra, dose spectra and dose equivalent spectra measured at the site of the phantom lung. The LET spectra measured for the three conditions - the bare phantom torso, and the phantom inside the EMU and Orlan-M suits - are all in close agreement with one another, indicating that the suits were not a significant source of target fragments to the lung. This result is further borne out in comparisons of the total dose, dose equivalent and average quality factor. Total dose corrected for high-LET particle contribution, dose equivalent and average quality factor determined from combined CR-39 PNTD and TLD measurements are given in Table 7, as are the dose and dose equivalents from target fragments, and the relative contributions to total dose and dose equivalent from target fragments. Both dose and dose equivalent are lower in the EMU and Orlan-M suits when compared to that measured in the lung of the bare phantom torso, illustrating the attenuation of the proton flux by the suits.

Table 7. Total Dose, Dose Equivalent, and Mean Quality Factor from $\sim 10 \mathrm{cGy}, 232 \mathrm{MeV}$ proton irradiations measured using CR-39 PNTDs and LiF TLDs in the phantom lung for the bare phantom torso, phantom torso inside the EMU suit and phantom torso inside the Orlan-M suit.

\begin{tabular}{l|c|c|c}
\hline Suit & None & EMU & Orlan-M \\
\hline \hline Total Dose $\left(\mathrm{cGy} /\right.$ proton $\left.\times 10^{-8}\right)$ & $6.99 \pm 0.54$ & $6.31 \pm 0.54$ & $6.35 \pm 0.51$ \\
\hline Change in Dose due to Suit & $\mathrm{n} / \mathrm{a}$ & $-10 \%$ & $-9 \%$ \\
\hline Dose $_{\mathrm{TLD}}\left(\mathrm{cGy} /\right.$ proton $\left.\times 10^{-8}\right)$ & $6.63 \pm 0.36$ & $5.99 \pm 0.19$ & $6.03 \pm 0.36$ \\
\hline Dose $_{\mathrm{PNTD}}\left(\mathrm{cGy} /\right.$ proton $\left.\times 10^{-8}\right)$ & $0.36 \pm 0.02$ & $0.32 \pm 0.01$ & $0.35 \pm 0.02$ \\
\hline Target Fragmentation Dose Contribution & $5.1 \%$ & $5.0 \%$ & $5.6 \%$ \\
\hline Total Dose Equivalent $\left(\mathrm{cSv} /\right.$ proton $\left.\times 10^{-8}\right)$ & $10.80 \pm 0.95$ & $9.68 \pm 0.30$ & $9.30 \pm 0.92$ \\
\hline Change in Dose Equivalent due to Suit & $\mathrm{n} / \mathrm{a}$ & $-10 \%$ & $-14 \%$ \\
\hline Dose Equivalent & $4.17 \pm 0.29$ & $3.68 \pm 0.01$ & $3.28 \pm 0.26$ \\
\hline $\begin{array}{l}\text { Target Fragmentation }\left(\mathrm{cSv} / \text { proton } \times 10^{-8}\right) \\
\text { Dose Equivalent Contribution }\end{array}$ & $39 \%$ & $38 \%$ & $35 \%$ \\
\hline Average Quality Factor & $1.55 \pm 0.18$ & $1.53 \pm 0.07$ & $1.47 \pm 0.19$ \\
\hline $\begin{array}{l}\text { Change in Average Quality Factor } \\
\text { due to Suit }\end{array}$ & $\mathrm{n} / \mathrm{a}$ & $-1 \%$ & $-5 \%$ \\
\hline
\end{tabular}



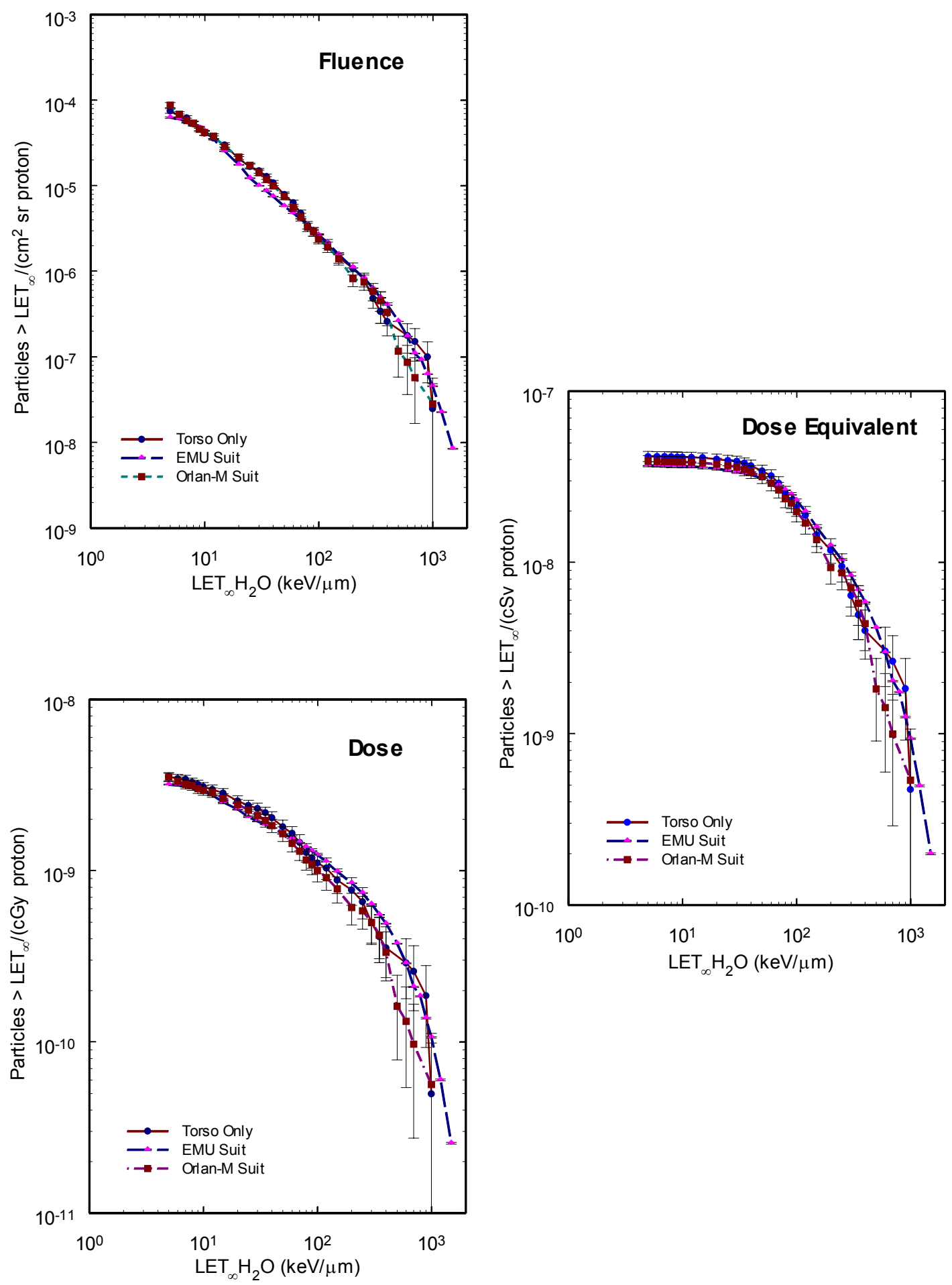

Figure 16. Integral LET Fluence, Dose and Dose Equivalent Spectra from $232 \mathrm{MeV}$ proton irradiations measured using CR-39 PNTDs in the phantom lung. 
The contribution from target fragments to total dose in the lung was $5.1 \%$ for the bare phantom torso, 5.0\% inside the EMU suit, and 5.6\% inside the Orlan-M suit. Similarly, the contribution from target fragments to total dose equivalent was quite close for all three measurements, with a $39 \%$ contribution for the bare phantom torso, a $38 \%$ contribution for the torso inside EMU suit, and a 35\% contribution for the torso inside the Orlan-M suit. Average quality factor was $1.55 \pm 0.18$ for the phantom torso alone, $1.53 \pm 0.07$ for the EMU suit, and $1.47 \pm 0.19$ for the Orlan-M suit. It appears that neither the EMU suit nor the Orlan-M suit added significantly to the target fragmentation dose and dose equivalent measured in the lung. However, it should be noted that a dummy chest unit and backpack were in used in place of the actual Display and Control Module and Life Support Unit during these irradiations and the dummy units were probably of very different composition than the actual flight hardware. Thus the effect of the EMU suit on dose and dose equivalent to the lung may not have been accurately measured.

\subsubsection{Stomach Exposures}

The integral LET fluence, dose and dose equivalent spectra measured in the stomach of the phantom for the bare phantom and the phantom with EMU suit are shown in Figure 17. As noted above, irradiations to the phantom stomach while inside the Orlan-M suit were not possible due to the single-piece construction of the Orlan-M suit and to the stand on which it was attached. The curves from measurements made with and without the EMU suit are in close agreement. The measurements made inside the EMU suit show slightly more signal from particles of LET $>300 \mathrm{keV} / \mu \mathrm{m}$. Table 8 gives the total dose, dose equivalent and average quality factor measurements made in the phantom stomach both with and without the EMU suit. Attenuation of the total proton flux can be seen in the smaller values of dose and dose equivalent in the EMU suit measurements. While the contribution to dose from target fragments was higher in the EMU suit- $4.6 \%$ versus $3.9 \%$ - contribution from target fragments to dose equivalent was little changed by the presence of the suit- $32 \%$ with the suit as compared to $31 \%$ without the suit. The average quality factor was the same for both situations: 1.40 . Since the suit adds little in the way of mass in front of the stomach, it is not surprising that there should be little difference between the two sets of measurements.

\subsubsection{Thigh Exposures}

A similarly close agreement between measurements made with and without the EMU suit in the phantom stomach is seen in measurements made with and without the EMU suit in the phantom thigh. As with the stomach irradiations, it was not possible to expose the phantom thigh while inside the Orlan-M suit. Figure 18 shows the integral LET fluence, dose and dose equivalent spectra measured at the site of the phantom thigh for the bare phantom and for the phantom inside the EMU suit. There is very close agreement between the two measurement conditions for the thigh in all three spectra, illustrating that the EMU suit in the area of the thigh adds little in the way of shielding. This observation can also be seen in comparisons of total dose, dose equivalent and average quality factor from the combined TLD and CR-39 PNTD measurements for the thigh, shown in 
Table 9. Both dose and dose equivalent are practically the same for the bare phantom thigh with and without the EMU suit. There is a somewhat higher dose from particles of LET $\geq 5 \mathrm{keV} / \mu \mathrm{m}$ in the bare thigh versus the thigh inside the EMU suit. However this high LET dose does not propagate to an increased dose equivalent and the $30 \%$ contribution from target fragments to total dose equivalent is the same for both situations. Average quality factor in the bare thigh is slightly higher than that measured inside the EMU suit, reflecting some attenuation of the proton flux by the suit.

Table 8. Total Dose, Dose Equivalent, and Mean Quality Factor from $\sim 10 \mathrm{cGy}, 232 \mathrm{MeV}$ proton irradiations measured using CR-39 PNTDs and $\mathrm{LiF}$ TLDs in the phantom stomach for the bare phantom torso and phantom torso inside the EMU suit.

\begin{tabular}{l|c|c}
\hline Suit & None & EMU \\
\hline Total Dose $\left(\mathrm{cGy} /\right.$ proton $\left.\times 10^{-8}\right)$ & $7.11 \pm 0.64$ & $6.55 \pm 0.21$ \\
\hline Change in Dose due to Suit & $\mathrm{n} / \mathrm{a}$ & $-13 \%$ \\
\hline Dose $_{\mathrm{TLD}}\left(\mathrm{cGy} /\right.$ proton $\left.\times 10^{-8}\right)$ & $6.79 \pm 0.42$ & $6.27 \pm 0.19$ \\
\hline Dose $_{\text {PNTD* }}\left(\mathrm{cGy} /\right.$ proton $\left.\times 10^{-8}\right)$ & $0.28 \pm 0.02$ & $0.29 \pm 0.01$ \\
\hline Target Fragmentation Dose Contribution & $3.9 \%$ & $4.6 \%$ \\
\hline Total Dose Equivalent $\left(\mathrm{cSv} /\right.$ proton $\left.\times 10^{-8}\right)$ & $9.93 \pm 1.07$ & $9.08 \pm 0.28$ \\
\hline Change in Dose Equivalent due to Suit & $\mathrm{n} / \mathrm{a}$ & $-9 \%$ \\
\hline Dose Equivalent & $3.10 \pm 0.27$ & $2.86 \pm 0.01$ \\
\hline Target Fragmentation Dose Equivalent Contribution & $31 \%$ & $32 \%$ \\
\hline Average Quality Factor & $1.40 \pm 0.20$ & $1.40 \pm 0.06$ \\
\hline Change in Average Quality Factor due to Suit & $\mathrm{n} / \mathrm{a}$ & $0 \%$ \\
\hline
\end{tabular}

Table 9. Total Dose, Dose Equivalent, and Mean Quality Factor from $\sim 10 \mathrm{cGy}, 232 \mathrm{MeV}$ proton irradiations measured using CR-39 PNTDs and $\mathrm{LiF}$ TLDs in the phantom thigh for the bare phantom thigh and phantom thigh inside the EMU suit.

\begin{tabular}{l|c|c}
\hline Suit & None & EMU \\
\hline \hline Total Dose $\left(\mathrm{cGy} /\right.$ proton $\left.\times 10^{-8}\right)$ & $6.95 \pm 0.59$ & $6.92 \pm 0.22$ \\
\hline Change in Dose due to Suit & $\mathrm{n} / \mathrm{a}$ & $-0.4 \%$ \\
\hline Dose $_{\mathrm{TLD}}\left(\mathrm{cGy} /\right.$ proton $\left.\times 10^{-8}\right)$ & $6.67 \pm 0.64$ & $6.67 \pm 0.21$ \\
\hline Dose $_{\text {PNTD* }}\left(\mathrm{cGy} /\right.$ proton $\left.\times 10^{-8}\right)$ & $0.28 \pm 0.02$ & $0.25 \pm 0.01$ \\
\hline Target Fragmentation Dose Contribution & $4.0 \%$ & $3.7 \%$ \\
\hline Total Dose Equivalent $\left(\mathrm{cSv} /\right.$ proton $\left.\times 10^{-8}\right)$ & $9.50 \pm 1.00$ & $9.51 \pm 0.30$ \\
\hline Change in Dose Equivalent due to Suit & $\mathrm{n} / \mathrm{a}$ & $0.1 \%$ \\
\hline Dose EquivalentPNTD $\left(\mathrm{cSv} /\right.$ proton $\left.\times 10^{-8}\right)$ & $2.83 \pm 0.24$ & $2.84 \pm 0.01$ \\
\hline Target Fragmentation Dose Equivalent Contribution & $30 \%$ & $30 \%$ \\
\hline Average Quality Factor & $1.37 \pm 0.19$ & $1.34 \pm 0.06$ \\
\hline Change in Average Quality Factor due to Suit & $\mathrm{n} / \mathrm{a}$ & $-2 \%$ \\
\hline
\end{tabular}


Eril Research, Inc.
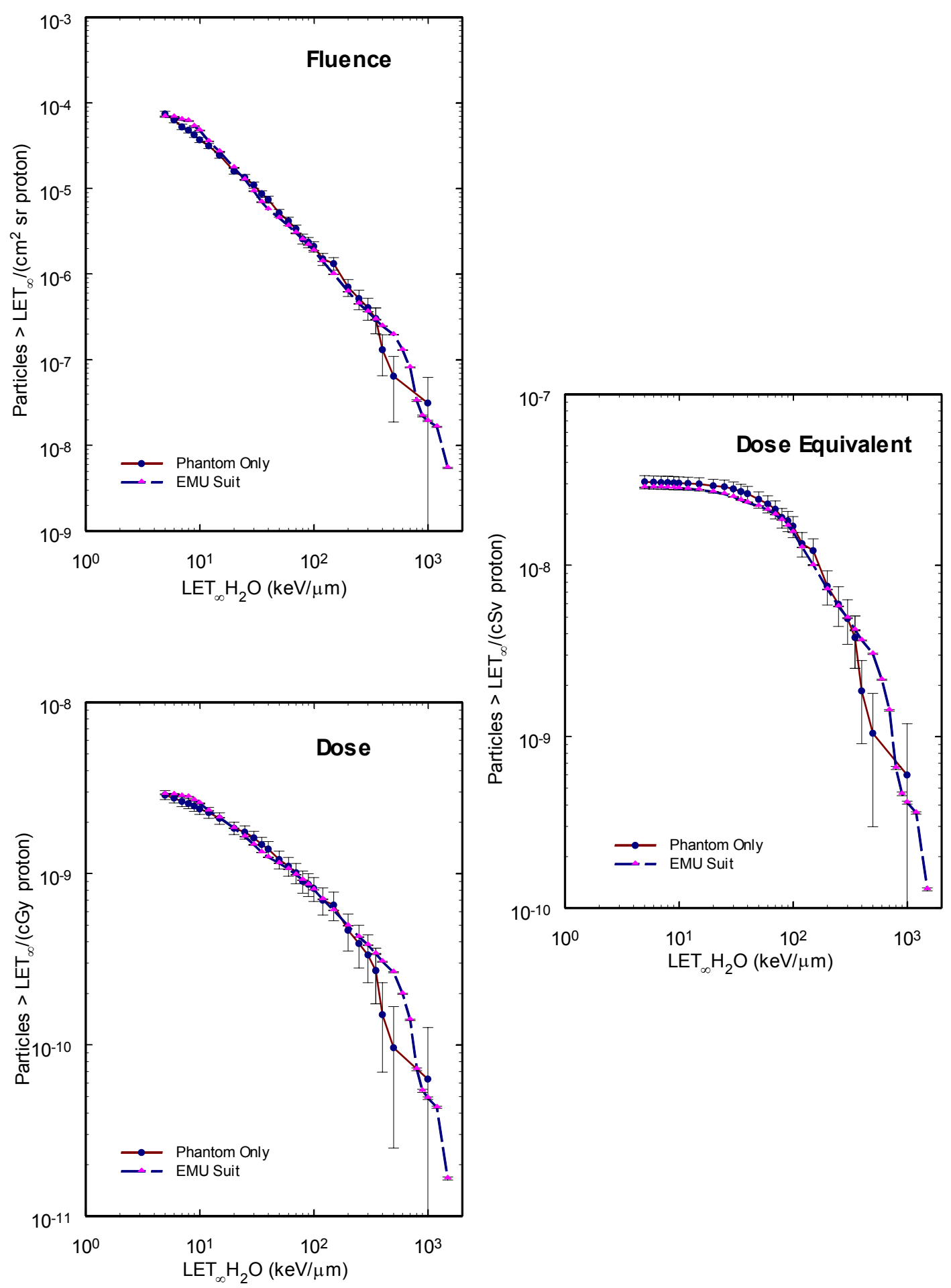

Figure 17. Integral LET Fluence, Dose and Dose Equivalent Spectra from $232 \mathrm{MeV}$ proton irradiations measured using CR-39 PNTDs in the phantom stomach. 

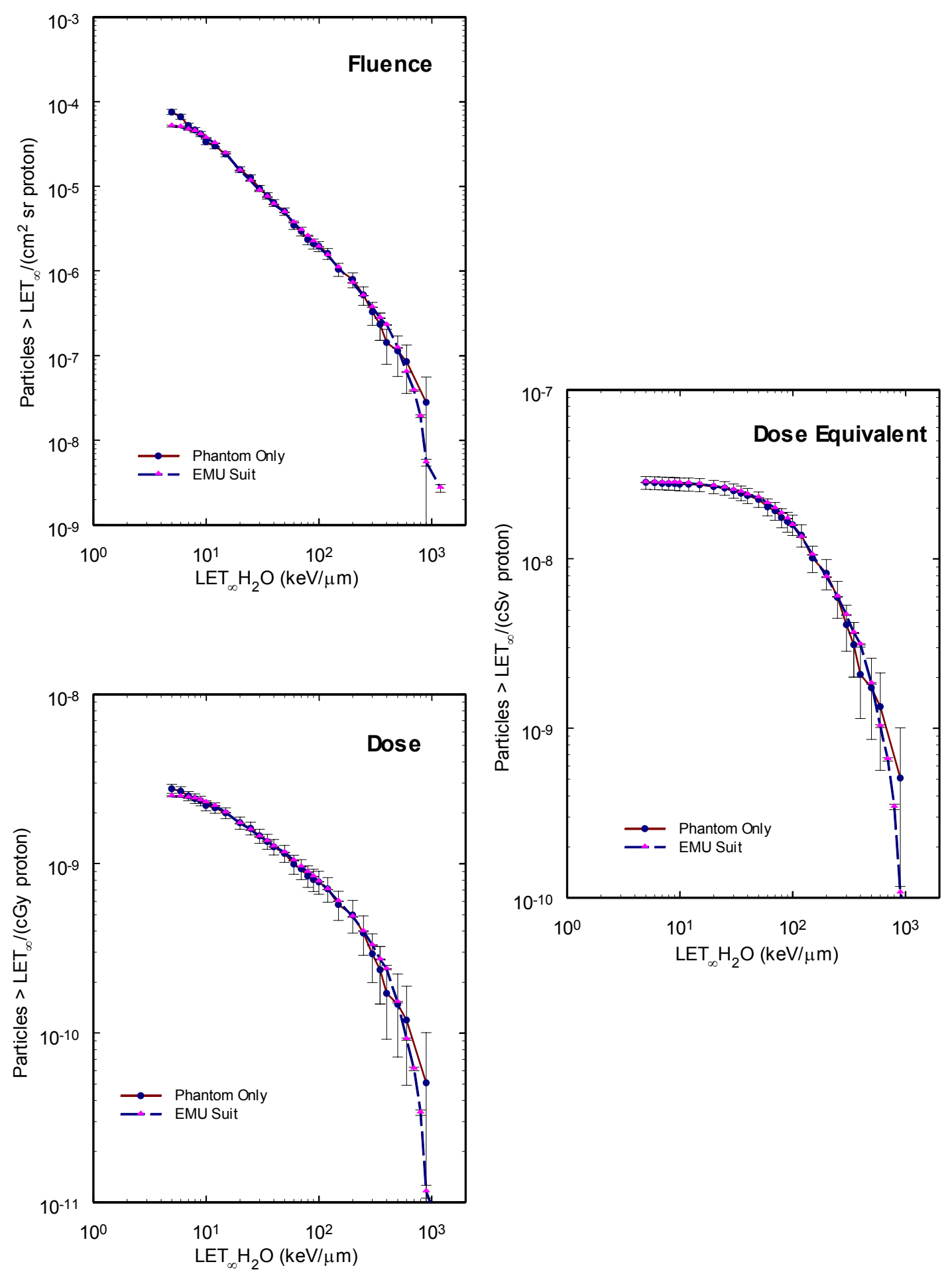

Figure 18. Integral LET Fluence, Dose and Dose Equivalent Spectra from $232 \mathrm{MeV}$ proton irradiations measured using CR-39 PNTDs in the phantom thigh. 


\section{CONCLUSIONS}

Measurements inside the NASA EMU and Russian Orlan-M EVA helmets and behind swatches of the NASA EMU and Russian Orlan-M EVA suit materials in exposures to 6 $\mathrm{MeV}$ electrons and $60 \mathrm{MeV}$ protons were analyzed to produce profiles of dose as a function of depth in water. The electron beam doses are reduced by as much as a factor of 5 (for the Orlan-M helmet exposure), showing the considerable attenuation of the electron flux within the mass of the suits. Further depth dose variations over $2.5 \mathrm{~cm}$ of water-equivalent vary only a few percent. This does not fit the expectations for a monoenergetic $6 \mathrm{MeV}$ beam where one would expect an initial dose buildup with depth to a broad peak, then a continuous decline to zero dose at the maximum electron range. Most likely there was significant scattering off of the coolant tubing and other surfaces within the suit materials.

The $60 \mathrm{MeV}$ proton beam exposures behind the suit swatches and inside the helmets resulted in dose/depth distributions which can be explained by an initial slowing of the beam in the suit, followed by a gradual slowing toward the Bragg peak in a $2.5 \mathrm{~cm}$ equivalent depth of water. Doses immediately behind the suit materials varied from 11 to 14 cGy, considerably greater than the $\sim 10 \mathrm{cGy}$ incident proton dose. The dose/depth distribution for the Orlan-M helmet exposure was somewhat different than the other three, suggesting that the beam may have passed through an area composed of different material thicknesses.

The most significant results from measurements made using passive detectors to characterize the shielding effectiveness of the NASA EMU and Russian Orlan-M EVA suits were derived from the $232 \mathrm{MeV}$ proton irradiations. The LET spectra $\geq 5 \mathrm{keV} / \mu \mathrm{m}$, total dose, dose equivalent and average quality factor were measured at five locations (eye, brain, lung, stomach and thigh) inside the tissue equivalent phantom both by itself and while inside the NASA EMU and Russian Orlan-M EVA suits. Absorbed dose was measured using a combination of two types of TLD - TLD-600, sensitive to thermal and epithermal neutrons, and TLD-700, insensitive to neutrons. Results for all quantities measured, except for thermal and epithermal neutron contribution, were significantly greater than values expected from $232 \mathrm{MeV}$ protons when neglecting secondary particles. Little indication of buildup of low energy neutrons in the body (lung/stomach/thigh) was noted from the TLD-600 doses. The comparison of doses from TLD-600, covered and uncovered by Gd thermal neutron absorber foil, and TLD-700 showed no appreciable dose from thermal or epithermal neutrons

Differences in total dose and dose equivalent between irradiations made inside the EMU and Orlan-M suits and those made with only the bare phantom are driven by three competing processes. The additional shielding represented by the suits tended to reduce both dose and dose equivalent through attenuation and scattering of the primary proton flux. The mass of the suits and the phantom body slowed the proton beam and increased the LET of the primary protons as they approached the Bragg peak. The increased LET led to increased dose and dose equivalent. Finally, proton-induced target fragmentation within the mass of the suit-most notably within the two EVA helmets - tended to 
increase total dose and especially dose equivalent through the production of high-LET secondaries. For the most part, the attenuation of the primary proton flux appeared to dominate over the slowing of the beam and the production of target fragment secondaries. Both the total dose an dose equivalent tended to be lower inside the two suits than in the bare phantom. There were two instances where the dose equivalent inside the suits was higher than that in the bare phantom, but in both cases - the brain measurement inside the Orlan-M helmet and the thigh measurement inside the EMU suit - the difference between the dose equivalent measurements made with and without the suits was less than $1 \%$.

The greatest attenuation in dose was seen inside the two EVA helmets. For proton irradiations through the back of the head, dose to the eye was $22 \%$ less inside the EMU helmet and $27 \%$ less inside the Orlan-M helmet than in the phantom head alone. Similarly, for proton irradiations through the visors, dose to the brain was $21 \%$ smaller inside the EMU helmet and 13\% smaller inside the Orlan-M helmet as compared to the bare head. The reduction in dose due to the suits was more modest in measurements made in the rest of the phantom body. Doses measured in the lung inside the EMU and Orlan-M suits were $10 \%$ and $9 \%$ smaller, respectively, than the lung dose measured in the bare phantom torso. Due to the way in which the Orlan-M suit was mounted on its stand and because the Orlan-M is a single-piece suit, it was not possible to make $232 \mathrm{MeV}$ proton exposures to the stomach and thigh inside the Orlan-M suit. Dose at the stomach inside the EMU suit was 13\% less than in the bare phantom stomach, while the thigh dose inside the EMU suit showed less than a $1 \%$ reduction from that measured in bare phantom.

Changes in dose equivalent due to the presence of the suits were also greater in the helmets than in the lower parts of the suit. However, the changes in dose equivalent were generally smaller than the corresponding changes in total dose. Dose equivalent measured at the eye was 14\% less inside the EMU helmet and 25\% less inside the Orlan-M helmet than for the phantom head alone. Inside the brain, the dose equivalent was lower by $8 \%$ for the EMU helmet and actually $0.5 \%$ greater for the Orlan-M helmet as compared to the measurement made in the bare phantom head. Dose equivalent measurements made in the lung were $10 \%$ and $14 \%$ less than in the bare phantom for the EMU suit and Orlan-M suit, respectively. Dose equivalent in the stomach while inside the EMU suit was $9 \%$ less than in the bare phantom and dose equivalent in the thigh while inside the EMU suit was practically identical to that measured in the bare phantom thigh.

Average quality factor increased when measured inside the two EVA helmets, but showed little difference with bare phantom measurements in the lower portions of the two suits. Average quality factor measured at the eye was $10 \%$ greater in the EMU helmet and $2 \%$ greater in Orlan-M helmet when compared to that measured in the bare phantom head. Similarly, average quality factor measured in the brain was $14 \%$ greater in the EMU helmet than in the bare head and 13\% greater in the Orlan-M helmet than in the bare head. For the lung measurements, average quality factor was reduced by $1 \%$ by the EMU suit and $5 \%$ by the Orlan-M suit. Average quality factor was unchanged in the stomach measurements by the shielding of the EMU suit and reduced by $2 \%$ in the thigh by the presence of the EMU suit. 
As expected, both the NASA EMU and Russian Orlan-M EVA suits were found to provide some shielding from the charged particle fluxes encountered outside the ISS. This shielding is most significant in the case of low energy protons and electrons. Previous measurements made by our laboratory on the exterior surface of the Mir Orbital Station showed a three orders of magnitude reduction in both dose and dose equivalent within the first $0.2 \mathrm{~g} / \mathrm{cm}^{2}$ of Al-equivalent shielding [8]. This large decrease is due to the attenuation of low energy protons and electrons. Note that the increased doses measured immediately behind the suit materials for the $60 \mathrm{MeV}$ proton irradiations are for a single proton energy. External to the ISS in LEO, protons will occupy a broad spectrum of energies both above and below the $60 \mathrm{MeV}$ protons used in this experiment. This broad energy spectrum will tend to smear out the dose distribution behind the EVA suit.

The helmets of the two EVA suits were found to reduce dose and dose equivalent from $232 \mathrm{MeV}$ protons - representative of proton energy in the broad peak of the trapped proton energy spectrum encountered in the SAA. There was also a reduction in dose and dose equivalent measured in the lungs due to the shielding provided by the suits. Little effect from the EMU suit was seen in measurements made in the stomach and thigh, areas where the suit is relatively thin. While proton target fragmentation added only modestly to the total dose- between 4 and $6 \%$-it made a significant contribution to the dose equivalent - between 30 and $40 \%$. It should be noted that this includes not only target fragmentation produced inside the suit, but also target fragmentation from the body of the phantom.

\section{REFERENCES}

[1] http://spaceflight.nasa.gov/station/eva/index.html

[2] Benton, E. R. and Benton, E. V. (2001) "Space radiation dosimetry in low-Earth orbit and beyond," Nucl. Inst. \& Meth. B, 184, Nos. 1-2, pp. 255- 294.

[3] Deme, S., Apathy, I., Hejja, I., Lang, E., and Feher, I. (1999) "Extra dose due to extravehicular activity during the NASA-4 mission measured by an on-board TLD system," Rad. Prot. Dos. 85 (1-4) 121-124.

[4] Benton, E. R., Frank, A. L., and Benton, E. V. (2000) "TLD efficiency of ${ }^{7}$ LiF for doses deposited by high-LET particles," Rad. Meas. 32 (3) pp.211-214.

[5] International Commission on Radiation Units and Measurements (1984) Stopping Powers for Electrons and Positrons, ICRU Report No. 37, ICRU, Bethesda.

[6] International Commission on Radiation Units and Measurements (1993) Stopping Powers and Ranges for Protons and Alpha Particles, ICRU Report No. 49, ICRU, Bethesda. 
[7] International Commission on Radiological Protection (1991) 1990 Recommendations of the International Commission on Radiological Protection, ICRP Report No. 60, Pergamon Press, Oxford.

[8] Benton, E. R., Benton, E. V., and Frank, A. L. "Dosimetric measurement of the radiation environment as a function of shielding made on the exterior of the Mir orbital station," Rad. Meas. in press. 